Historic, Archive Document

Do not assume content reflects current scientific knowledge, policies, or practices. 



\section{Strawberries Every Month in the Year}

3 and on three feet square if you like.
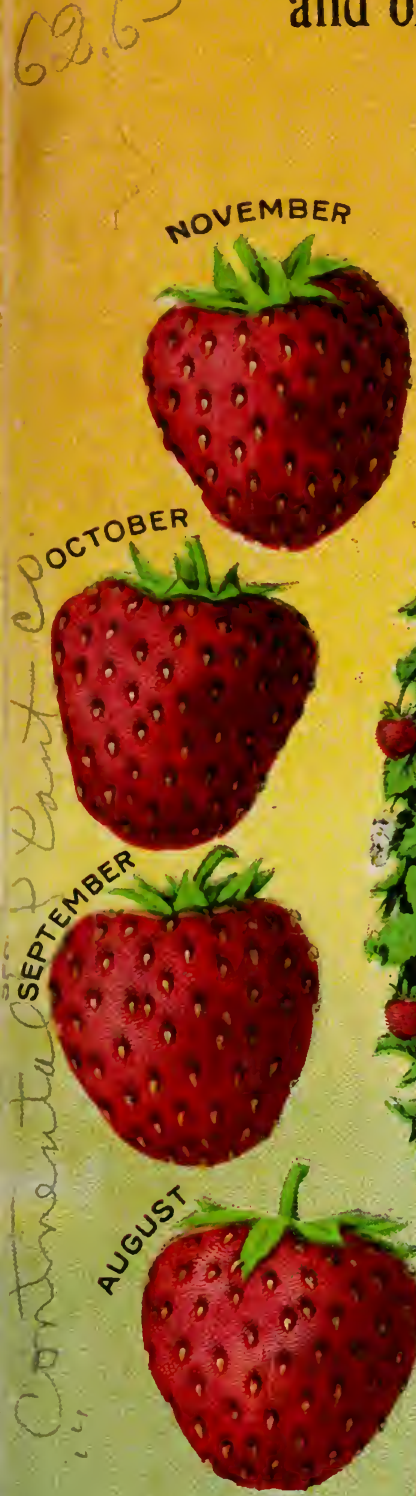

April to November in field or garden at North; at South all year round.

January to January in Barrel anywhere.
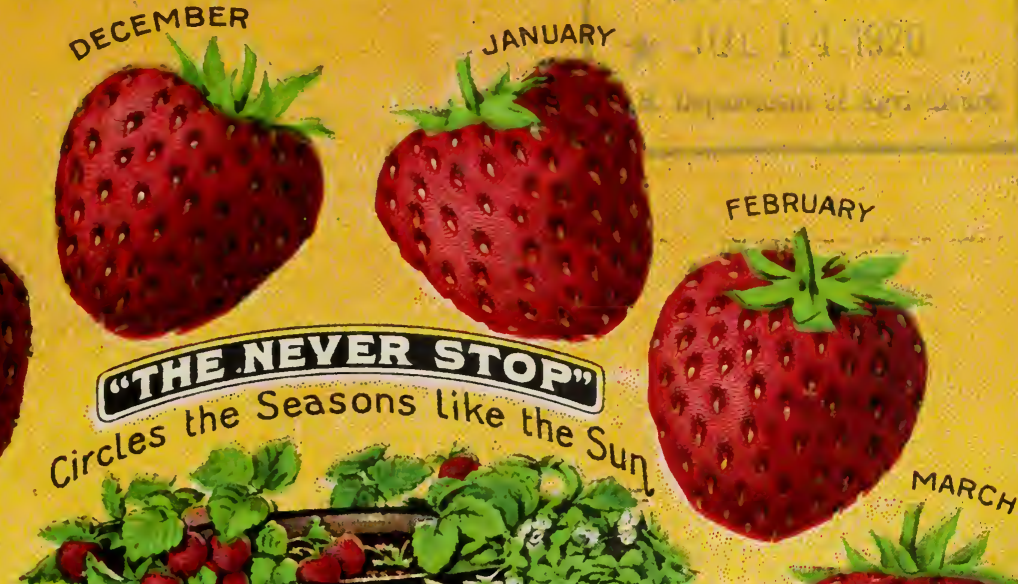

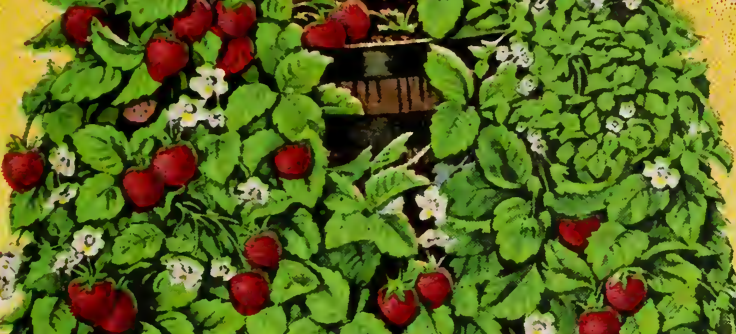

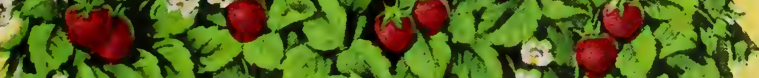

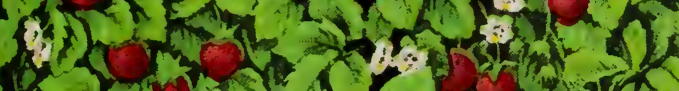
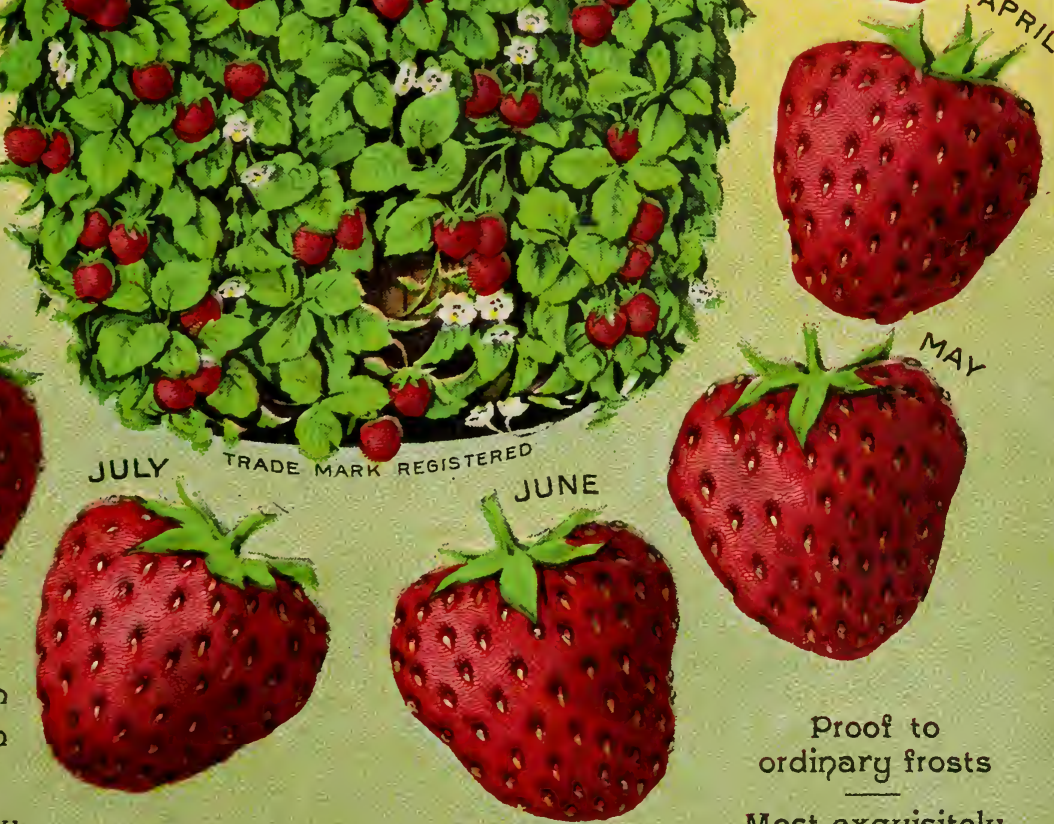

10,000 QUARTS TO THE ACRE
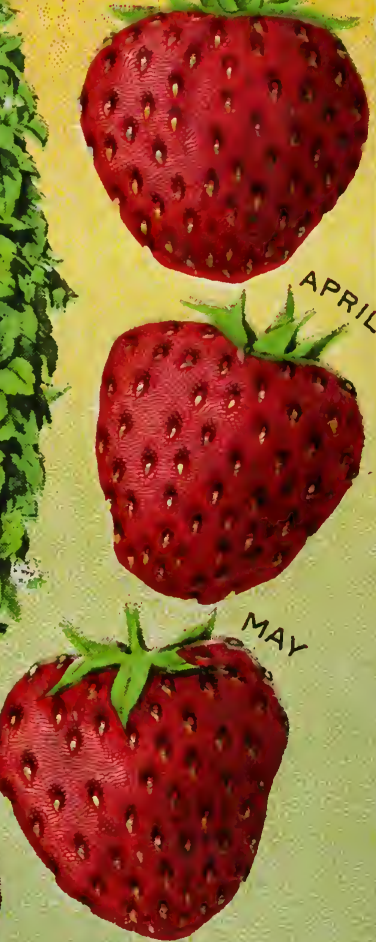

Proof to

ordinary frosts

Most exquisitely SELLS READILY AT $25 C$ QT.

$A$ vision of beauty for yard, porch, living room or conservatory. A solid mound of emeralds, pearls and rubies. - Flowers, fruit and foliage-year in and year out. 


\section{INDEX}

The Proper Soil for each Tree and Plant (Don't fail to read.) Page 3, etc.

Strawberry Plants. (The Never Stop, an exquisitely flavored Everbearing Stı and other varieties.) Page 10, etc.

Peach Trees. (Varieties ripening from May to Nov., including the Never finest and earliest of all peaches and the only one that never misses a crop.) Page s.,

Apple Trees. (Including the summer Ambrosia and the fall Ambrosia, the ir delicious of all apples.) Page 19, etc.

Pear Trees. (Varieties ripening from June to Dec.) Page 21, etc.

Japan Plum Trees. (In size, coloration. delightlul flavor and productiveness, genu revelation, especially the delicious Banana Plum.) Page 18.

Cherry Trees. Page 22.

Pecan Trees. (Orchards of the right varieties are the best paying investments in $t$ country.) Page 24.

Raspberry. (The famous Regis Everbearing and others) (Dewberry and Blackber Plants.) Page 22.

Japan Walnut Trees. (An excellent nut that thrives in this country.) Page 22.

Everbearing Mulberry Trees. (Worth $\$ 100$ each for pigs and poultry.) Page 22.

Fig Bushes. Page 24.

Evergreen Hedge Plants. (Amoor River Privet, California Privet. Grown on sr identical with its original home on the Amoor River in Siberia and conceded to the finest in the country. Perfect hedge first year.) Page 31-32.

Shade Trees. (The magnificent Umbrella Tree, handsomest of the tree world, $\mathrm{tl}$ quick growing silver maple, etc.) Page 31.

Evergreens. (Spruces, Arbor Vitaes, etc.) Page 30.

Grape Vines. ('The leading varieties of bunch grape and also Scuppernong and James Page 23.

Rose Bushes. (Hardy, field grown, will bloom heavy first year.) Page 29, etc.

Cabbage Plants. (Grown in the open air on South Carolina Coast. Sure to live, sure head and sure to pay.) Page 3i.

Asparagus, Rhubarb and Horse Radish Roots. Page 23-24.

Chickens and Eggs. (Blue ribbon strains only.) Page 24.

Collections of Plants, Trees, etc. delivered free. (Nothing else in the catalogue is delivered free.) Pages 25 and 26.

Price List. Pages 33 and 34.

How to Plant Strawberries. (How to grow them the whole year around, on 3 feet square.) Page 9.

How to Plant an Orchard. (Selection of location, soil. etc.) Page 14.

How to Beautify a Home. (How to plant hedges, shade trees, etc.) Page 27-28.

Full Cultural Directions and subsequent treatment of all above is given in our 100 pao manual which is free with every order for $\$ 5.00$ or over if asked for.

In writing about an order never fail to give its number as shown in the receipt sent yo

\section{OUR REFERENCES :}

Bank of Kittrell, Kittrell, N. C.

Citizens Bank, Henderson, N. C.
First National Bank, Henderson, N. C. Citizens National Bank, Raleigh, N

Find out all about us by enquiring of any or all of the above, inclosing star envelope for reply. 


\section{Different Soils the Young Fruit Trees Must Start In to do Their Level Best.}
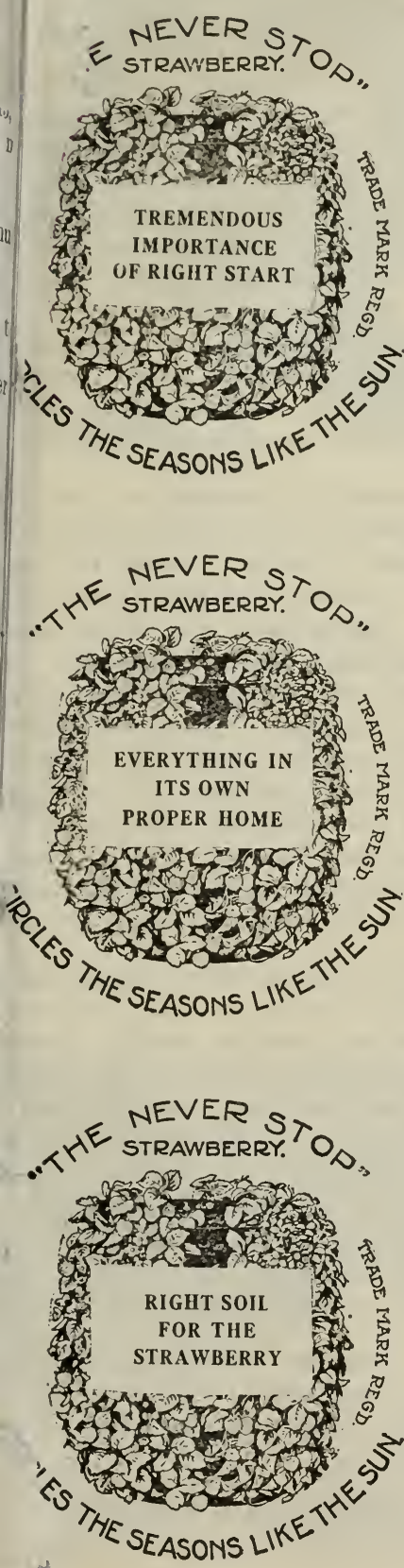

The future worth or worthlessness of everything that grows-of plant, tree, animal-aye, even of man himself, depends tremendously upon the start they get.

How shall we give plant or tree the right start; for it is with the plant and tree world that we are here concerned. And what is the right start. It is easy to give size. That is a mere matter of manure. When carried to excess size works positive harm. For an overgrown tree or plant gets such a severe shock in transplanting that it is less apt to live and grow off than even an undersized one, besides being rendered more susceptible to drought, disease or any untoward conditions that may assail it. But we hold no brief for the underling tree. Avoid that, too. Select the stout, "stocky," medium size tree or plant.

So the right start means much more than this mere matter of size. It means the bestowal of that mysterious gift which we call potentiality, and which means latent power to produce results when the time comes. Only when working hand in hand with nature can men bestow this quality; and nature aids him in exact proportion as each species of plant or tree is grown in its own proper habitatthat is, the soil and climate in which she placed each when she called it into being. The nearer to these conditions the plant or tree can spend its young life, the fitter it is to thrive in less favorable soil and climate when transplanted to them.

Lets take the strawberry plant first. It was only yesterday, comparatively speaking, that man reduced the strawberry to cultivation from its home in the hilly regions of the world. It still stands very close to nature-so close that to do its best the young plant must be started in nature's own domain on "new ground" - freshly cleared land. Only on this virgin, uncontaminated soil can the plant store that immense fund of vigor and vitality which fits it to do its level best in all soils and climates. And of all the plant world none bears as heavy a burden of fruit in proportion to its size as the strawberry.

\section{Strawberry Plants Shipped in Perfect Condition up to June 15th.}

In the southern and central parts of the country the strawberry can be set at any time during fall, winter or spring that the ground is not actually frozen or miry. the earlier the better. To those who can not plant early and for those farther north who have to plant later we can supply as late as June 15th plants in a perfectly dormant state, guaranteed to arrive by express in perfect condition no matter what distance. Properly set, these plants will live and grow fast no matter how hot and dry it is. But order must call for dormant plants.

\section{PLANTS BY FREIGHT AT 25 CENTS PER THOUSAND.}

Usually from November 15 th to March 15 th or April 1st (according to weather) they can safely be sent by freight any distance at about $25 \mathrm{cts}$ per 1.000 . Must be ordered in lots of 5000 or over to get this low rate as the freight charge is by the 100 Ibs. But better leave mode of shipment to us always. We will consider all circumstances and act for the best. See pages 11 and 33 . 

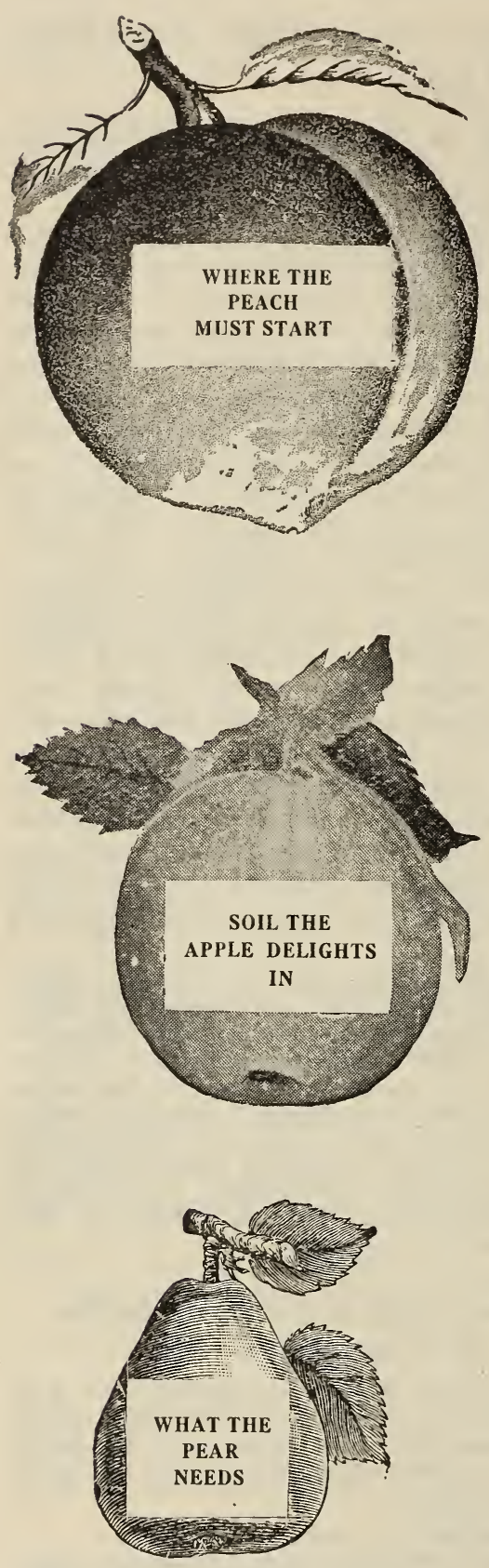

The Peach thrives throughout almost as vast an extent of latitude and diversity of climate and soil as the strawberry itself. That is, the properly started peach does. For nothing is more susceptible to soil conditions than the young peach seedling. Only on a stiff clay soil too hard for borers and insect enemies does it find that immunity from danger that enables it to grow unscathed, smooth barked, clean limbed, ready to get down to business and to stick to it for twenty years and more. A peach tree grown in such soil and with proper care will begin to bear in two years, bear heavier and better crops and the orchard will last longer than trees less favorably grown. Fine peach orchards are found growing on all soils except those given to wetness-on sandy, clayey, gravelly soil-but the peach nursery, the home of the young trees must be on stiff clay if great results are to follow.

The Apple is also much of a cosmopolite. You find apple orchards thriving on a wide range of soils and through many degrees of latitude, though the very finest apples have a penchant for high places, they will hug the hills. Nevertheless the young apple tree is even more squeamish than the peach as to the soil it begins life in. No stiff soil for your young apple tree nor any hint of it. Such soil free from enemies of the peach, is strange to say full of enemies of the apple. The young apple tree is at its prime only when grown on thoroughly drained sandy loam, of sogginess, wetness, there must not be even a hint. Only here where free from crown knot, gall and aphis is it clean and lusty, full of vigor as an egg is of meat.

Pear Trees require conditions almost diametrically opposite to the apple to start in. Only on moist, peaty loam. such as are found in recently drained swampy places, does the young pear tree root heavily and grow fit for early work and long. Otherwise unless the season happens to hit just right they are apt to get stunted. It is the instinct of the pear to set an enormous crop of fruit and there must be a wealth of root growth to answer the heavy drain. A sufficiency of root growth is impossible except of the very richest soil with enough moisture right at hand.

Cherry Trees hate wet feet even when old; when young they simply cannot abide them. The Cherry nursery must stand on gravelly hills or failure is the result.

Grape Vines love sandy slopes, sunny but not too dry. Here they get a start that enables them to thrive on almost any soil under the sun. 

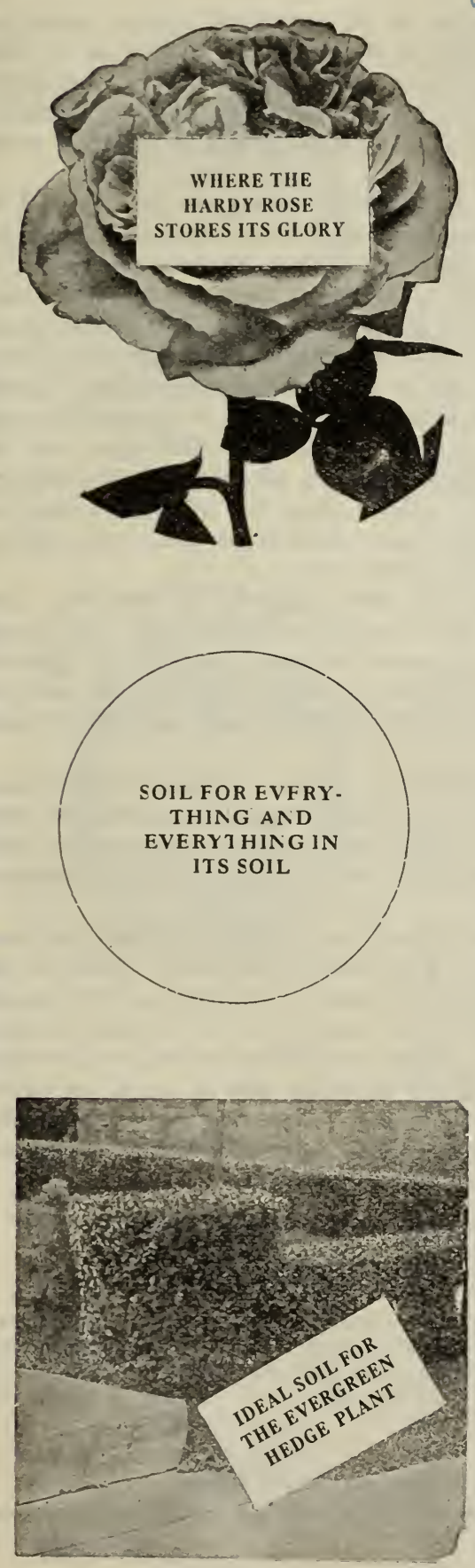

ROSE BUSHES and Evergreens are exceedingly fastidious as to a starting place. The rose cutting is rooted in sand and under cover. But it must then be transplanted to a dark, very rich clay. Here in the open it grows stout and stocky, storing power to burst into an endless wealth of blooms the first year and to continue to do so on any soil. Evergreens need the same soil as the rose.

SHADE TREES.-The Umbrella Tree, the Maple. The umbrella tree had its origin in the deep, moist, alluvial lands of the Southwest. The maple's home is on similar land along the streams. It is on such soils that the young trees of each get the right start which enables them to thrive almost everywhere and to give the best shade in the shortest time.

HEDGE PLANTS.-The evergreen privets revel in deep" alluvial soil. On no other can they attain the immense root growth absolutely essential to a perfect hedge the first year. This is the soil of the Amoor River region in Siberia their native home.

\section{HOW NATURE MADE AN IDEAL NURSERY REGION.}

Now any geologist will inform you that scarcely anywhere else on the globe are as great a variety of soils thrown in juxta-position as in the North Carolina hills. This is the result of the wearing down through the millions of years of the mountains to the back of them, one of the very oldest mountain chains in the whole world; and a chain especially in its North Carolina section producing a greater variety of minerals and therefore of soils than any other mountains in the world. It is a well acknowledged fact that in this State is to be found a greater variety of minerals than in any other division on earth.

Our dozen farms situated right in the heart of the North Carolina hills embrace a greater variety of soils than could doubtless be found in the same neighborhood anywhere on the continent outside of this region.

We have in easy reach, in fact almost side by side, the stiff, red clay for the peach, the well drained sandy loam for the apple; the gravelly hills for the cherry; the dark stiff clay for the rose and evergreen; the deep sand for the grape; while in some of the pockets among the hills are found the black peaty soil for the pear and in others the accumulation of sand and humus which reproduce closely the soil along the Amoor River in Siberia where the famous Amoor River privet originated and which enables us to absolutely defy competition in producing an evergreen hedge plant that will make a better hedge and make it quicker than those grown anywhere else. Our hedge plants have repeatedly been subjected to the severest competition test in competing for big orders and have captured the ,business every time. 

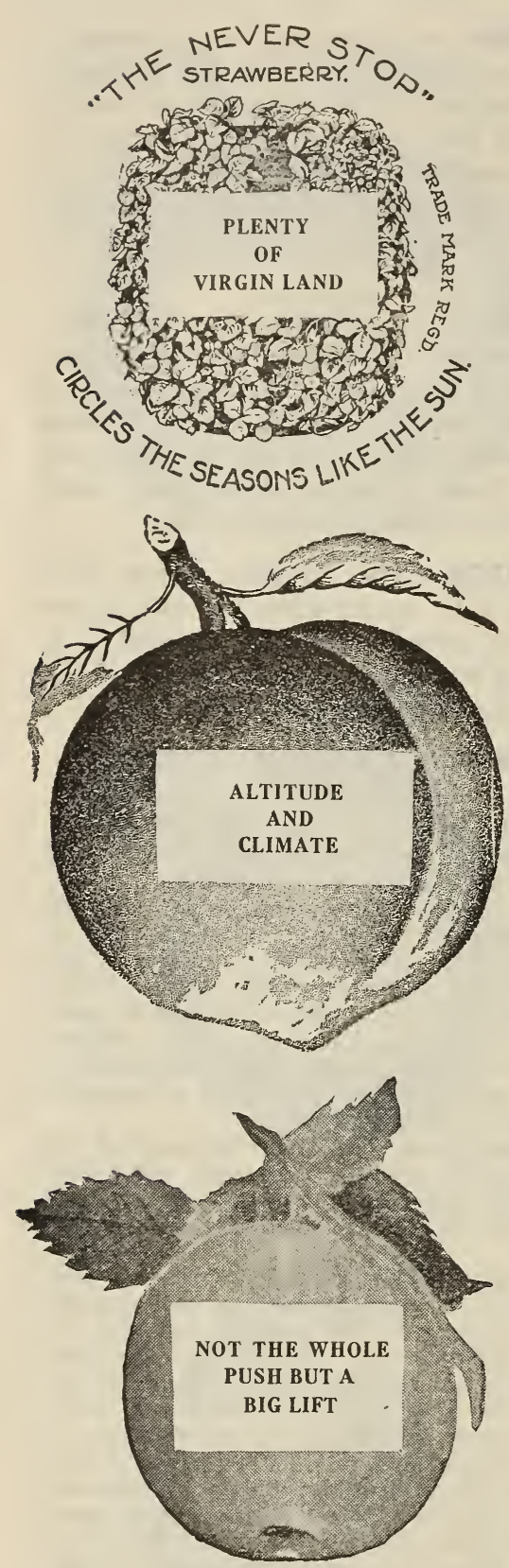

Last but greatest of all, our farms embrace plenty of wooded land which we clear year by year so as to grow the strawberry plant on virgin soil, soil also so thoroughly adapted to the growth of the strawberry that in the chance unwooded spots it is found growing wild in matchless excellence.

Moreover we are situated midway the country and at about an average altitude. This advantage combined with that we are in a region where the strawberry even in wild state attains a perfection unrivalled anywhere else in the world, where the grape grows wild in profusion and fruit of all kinds thrive amazingly, makes plants and trees grown here at home in all parts of the country. Again situated as we are with the Gulf Stream on one hand and the mountains on the other the destructive droughts that all too often devastate almost every other region of the country are unknown here. Never since the white man came in 1739 has the region known a year so dry that proper cultivation would not make a good crop.

Temperatures are also comparatively equable. The winters usually mild, not often falling below $15^{\circ}$ above zero. While the favorable summer climate of the place is attested by the fact that Kittrell in the old time was the leading watering place of the State, as it was later a noted winter resort.

This long, mild-growing season is of immense advantage, especially to friut trees, as it gives the young wood on them full time to mature, removing all danger of injury from cold both in our nurseries and when transplanted to the orchards of our customers.

Now that the above is the whole push-that even these advantages will do it all-we do not claim. What we do claim, and our claim is backed by thirty years triumphant tests, is that plants and trees grown under these favoring conditions of soil, climate and cultivation are as good everywhere as those grown anywhere and so much the better than the common run that progressive growers, men who want the very best results, can not afford to ignore the facts above in brief laid before them.

\section{WHY NOT INSURE YOUR STRAWBERRY CROP AGAINST THE ANNUAL LOSS. THE POLICY COSTS NOTHING.}

Suppose the great railway or manufacturing interests of the country were to discover that they were annually losing 25 per cent. of their gross returns. What activity there would be, what millions, yea what billions, if necessary, would be spent to stop it. 

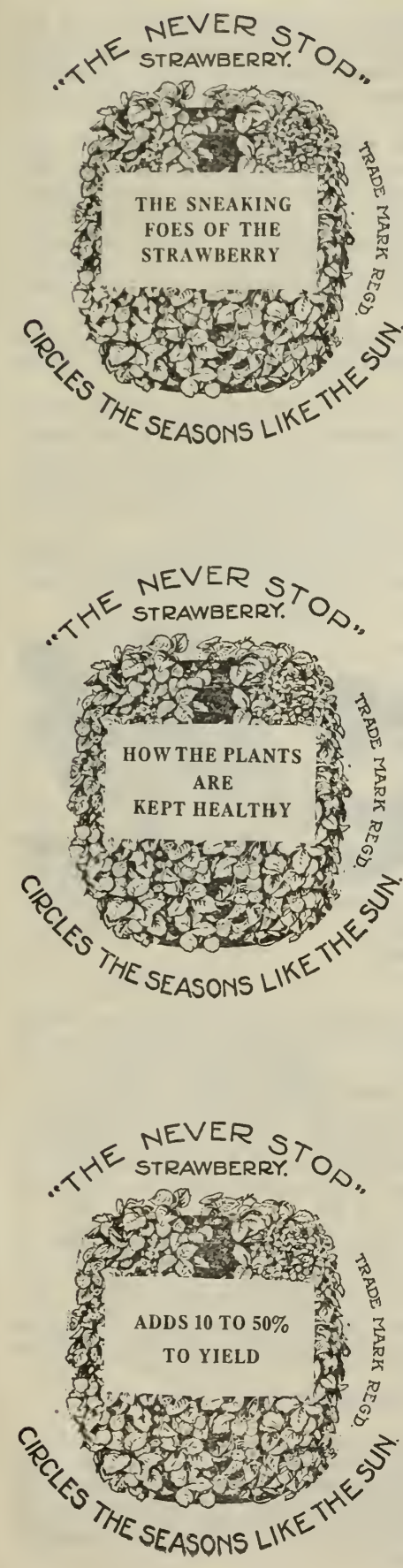

It is a well-known fact that rust and obscure fungous diseases are every year robbing the strawberry growers of the whole country of at least that much of their gross returns. Not only of their profit, mind you, but of their whole"product.

No cranny, no corner of the land is free from these diseases. They cover the whole country like dew. During the summer they make their presence known by dead and diseased leaves, sapping the vigor and the vitality of the plant. The result is that when fruiting time comes, the plant lacks stamina-backbone-to stand up to business. And no plant on earth, in proportion to its size, bears as heavy a crop as the strawberry-has as much strain put on it; and unless it is in perfect health the fruit suffers in proportion, both in quantity and quality. This effect is much increased by the peculiar manner in which the strawberry fruits. It fruits on a long stem. If there is rust or disease in the plant, it greedily seizes upon these tender fruit stems as soon as they appear, weakening them and cutting off nourishment from the berry.

As stated, these diseases are obscure. They don't proclaim their presence with a loud voice. But plant an acre in the ordinary run of plants and then another acre in plants free from this disease, pick and sell each separately and then count your dollars. That's your true logic.

The virgin soil in which we grow the strawberry plant is practically free from these diseases. But to make assurance double sure we have adopted a heroic remedy or rather preventive. The ordinary spraying methods are utterly futile with the strawberry. . It is as impossible to eradicate these diseases in the low close-growing plant by spraying as it would be to extinguish a house afire on the inside by sprinkling water on the roof. Therefore, before setting we strip every plant to the bone. That is, every leaf is pulled off down to the tiny, unopened bud, thus leaving nothing to harbor disease. The plant is then soused head and ears in a strong liquid fungicide and planted at once on fresh land. This is repeated every year. The result is that the plants we grow and sell are free from these diseases, and no matter how prevalent they are with you-and they are everywhere-will be but little affected by them for the first year or two, and will bear more and better fruit than plants whose parents were not thus treated. This method involves much trouble and expense, and calls for no little skill in mixing the fungicide just strong enough, and not too strong, but it results in the plants that have made our business famous and made it the largest of its kind in the world. Second in importance only to the above is the fact that our entire output of plants are grown from parent plants that are not allowed to weaken themselves by fruiting. This throws all the vigor in the young plants. 
THE STRAWBERRY.-It seems as natural for everybody to love it as they say it is for everybody to love a lover. It appeals so irresistibly not only to the palate - the strawberry we mean now; that is unless you happen to dwell on the Congo, then that other comestible might touch you closest-it appeals so irresistibly to divers senses; it is so beautiful, so fragrant and so delicious withal that the whole world loves it.

Mind you we mean the natural strawberry, the real one, not the commercial one. $\mathrm{He}$ who knows only the stale underripe berry of the mart can have but a slanderous notion of this Queen of Fruits. We mean the berry that Mother Nature made to eat, not the one that brother man makes to sell. We mean the right strawberry ripened to the last blush on your own vines and gathered by your own hand with heaven's dew all a-glitter upon it. There's your true ambrosia. There's your food for the gods and men and your medicine, too. For than the thoroughly ripe and freshly gathered strawberry of the right variety nothing is more wholesome even for invalids.

And how easy it is to grow. A small plot in the garden or lacking that a sunny space three feet square and a barrel or box and enough soil to fill them and this Queen of Fruits in all its glorious freshness is yours.

HOW TO PLANT IN GARDEN OR FIELD.-Select a plot on which strawberries have not recently been grown. If already rich no manure will be needed at the start. If not broadcast at the rate of twenty large loads of well rotted stable manure and a ton of hardwood ashes to the acre and mix thoroughly with soil by plowing or spading. Lacking these a ton of fertilizer analyzing about 4 per cent. ammonia; 10 per cent. potash and 10 per cent. phosphoric acid will answer. If used only in the drill (row) only $500 \mathrm{lbs}$. an acre should be applied.

Plant in rows $2 \frac{1}{2}$ or 3 feet apart, as your land is limited or not, setting the plants 15 in. apart in the row. It is of the first importance that the plants be set neither too deep nor too shallow. See the following illustration:

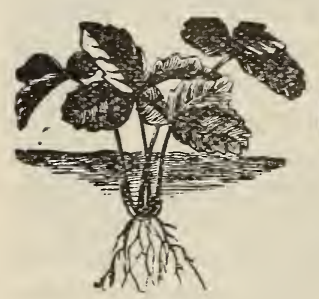

Set too deep

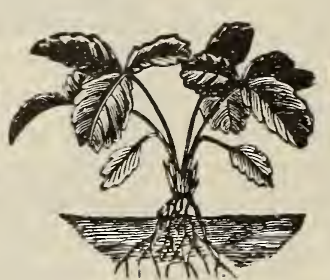

Set too shallow

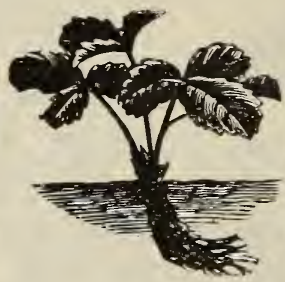

Set wrong. The roots should be spread fan-shaped

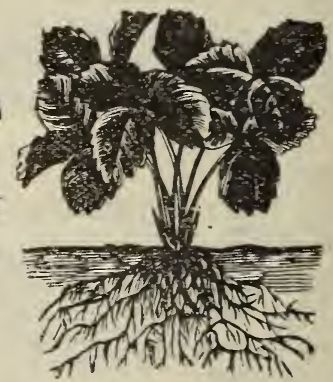

Set just right

Give shallow cultivation often enough to kill all weeds and grass before they come. Clip the runners as fast as they come or you will have a wilderness of young plants at the expense of fruit.

But this treatment does not apply to Never Stop. Set those plants in rows three apart, with the plants $18 \mathrm{in}$. to two feet apart in the row. Allow a moderate number of young plants to set around and between the parent plant. This is necessary because the young plants begin to bear just as soon as they take root and continue bearing till hard freezing winter sets in, the blooms being proof to ordinary frosts. At the South with straw protection in cold snaps it will fruit the year round.

Lack of space here forbids more detailed direction. But full and complete directions as to soil selection, planting, manuring, cultivating, gathering and selling all kinds of fruit is given in detail in our 100 page Manual which is free with every order of $\$ 5.00$ or over if asked for.

CONDITIONS OF SALE.-Under our rigid system of marking trees, plants, etc., it is almost impossible for an error to occur. But if it should. and the wrong variety of any fruit be sent, we will replace it free or refund the m.oney on satisfactory proof of the error. But further than this, we will not be responsible in any respect, and all stock is sold on that understanding, and no other.

\section{CONDITIONS OF SALE AND GUARANTEE UNDER WHICH NEVER STOP STRAWBERRY PLANTS AND NEVA-MYSS PEACH TREES ARE SOLD.}

To every shipment is attached a tag stating that while the purchaser of Never Stop strawberry plants can raise all the young plants wished for their own use they will part with none old or young; that the buyer of Neva-Myss peach trees will neither propagate or suffer to be propagated any trees from those sold him; that averse to this agreement plants or trees must be returned at our expense and money will be refunded; that by retaining plants or trees the buyer thereby becomes a party to above contract. The names Never Stop and Neva-Myss or Early Wonder are trade-marks and all persons are hereby warned not to use either or to sell such plants or trees. A man can, of course, sell his land on which Neva-Myss or Never Stop are growing, calling the attention of the buyer to above agreement as to trees or plants. (See page 2 for our bank reference.) 

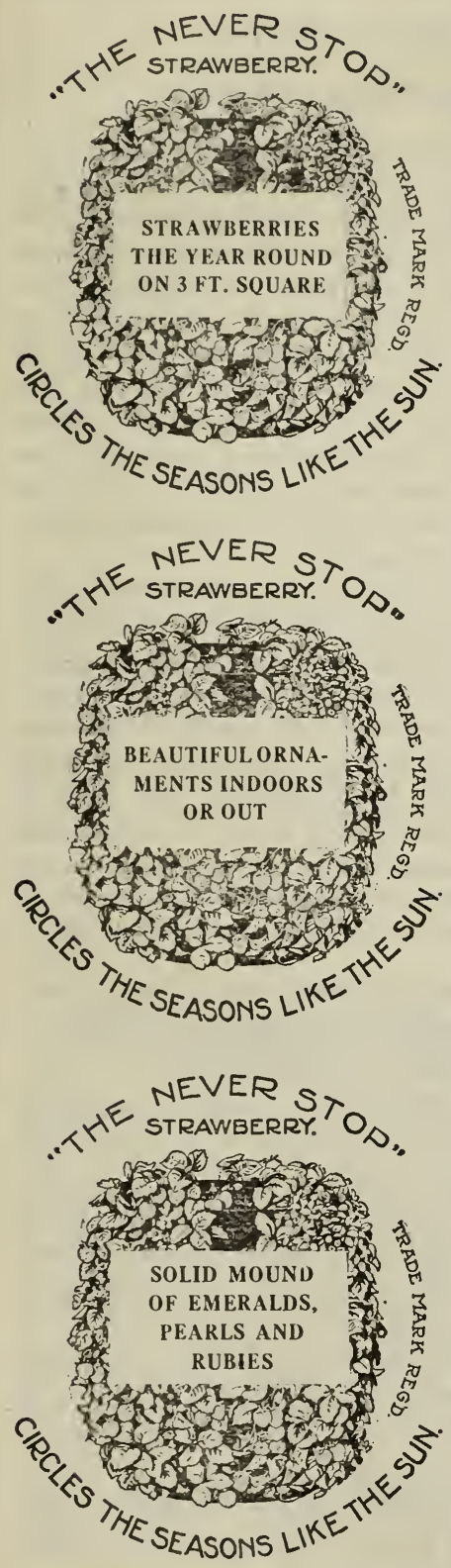

\section{STRAWBERRIES THE YEAR ROUND IN A BARREL.}

Growing Strawberries in a Barrel. Seekest thou a sensation? Wouldst be surprised, astonished, amazed? Wouldst work a miracle? Then get thee a barrel (or box) knock out one head, paint it for looks, bore the sides full of $1 \frac{1}{3}$-in. auger holes about 5 in. apart, total, say 100 . Fill the barrel with rich soil, setting a "Never Stop" plant in each hole as you fill it. Then bide a bit. Your barrel has vanished. In its place stands a solid mound of Emeralds, Pearls and Rubies (Foliage, Fruit and Flowers). Never worked Magician's ring a greater transformation; never Fairy wand called into being a vision of greater loveliness a more beautiful ornament for yard, flower garden, green house or conservatory. It is magic, rank magic one would say.

The quantity of fruit that can be grown this way is much more than would be expected. To see a barrel after it gets squarely down to business you would say that it would in a season bear a quart to each plant.

These plants will begin to bloom and fruit within six weeks after planting. This is true no matter what time of the year they are set excepting, of course, out-of-doors in winter at the North. At the South they can be set at any time of the year and will bloom and bear some fruit straight on through an ordinary winter if an old blanket or rug is thrown over the barrel in cold snaps. The blooms are proof to ordinary frosts.

At the North a barrel can be fruited fully seven months in the year if protected as stated in the cold snaps of early spring and late fall. And as winter comes on it can be carried in the greenhouse or conservatory where it will continue to bear all winter.

The one requisite indoor or out-in yard, porch, garden, conservatory or greenhouse is that the sun must shine on the barrel all day.

Full directions for planting, manuring and working garden plot and barrel is given in our booklet, which is free with every 100 Never Stop plants. With it success is certain.

\section{IMPORTANT.}

In garden culture of Never Stop be sure to clip all runners except enough to make not over twelve young plants to each old one. The fewer young plants in reason the larger and more constant the fruiting. Neither in garden or barrel is it good to use much manure or fertilizer too rich in ammonia or too much water. We find that the Never Stop does well on good garden soil without any manure at all except one pound of fertilizer to each running ten yards. The fertilizer should show about 3 per cent ammonia, 6 to 10 per cent potash and phosphoric acid.

I bought 8,000 strawberry plants from you. My truck man died and I had to take charge of them myself. I followed your Manual in every way and am glad to say I made money on them. I made berries from these plants so large that sixteen weighed a pound I am selling them at 25 cents a quart while all others have sold two quarts for 25 cents. 

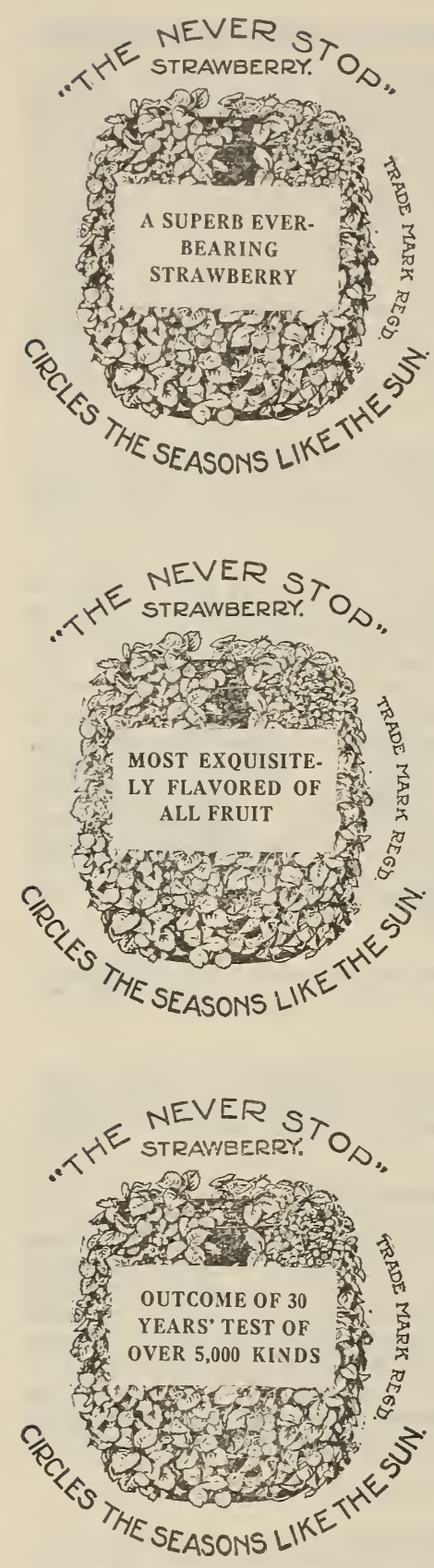

\section{The Never Stop.}

\author{
The Great Ever-Bearing Strawberry.
}

Almost ever since the strawberry was reduced to cultivation man has striven to improve it along three separate lines. Some have directed their energies to increasing its productiveness; others to improving its quality, its flavor and still others to extending its period of fruiting, to find the nearest approach to an ever-bearer. No one that we have ever heard of have striven specially to combine all these rare qualities in one variety. That would have been too much like fighting a lottery with one prize in a billion. But sometimes nature at long intervals does of her own accord what man might have striven for in vain till the crack of doom, and then with her lavish hand throws into boot qualities he scarcely dreamed of.

This she has done with the Never Stop Strawberry. She has made it a never failing, absolutely reliable ever-bearer. She has made it the most exquisitely flavored of all fruits. She has made it one of the most productive of all strawberries. But she did not stop there. In giving it the everbearing habit she added to it a quality lacking which the everbearing habit would be largely useless. She made it frost-proof-that is proof to ordinary frost. To do all this she had, of course, to bestow extraordinary vigor on the plant. This vigor enables it to begin fruiting almost immediately after planting and to keep everlastingly at it.

\section{OUTCOME OF 30 YEARS' TEST OF OVER 5,000 VARIETIES CARRIED ON IN THE NATURAL HOME OF THE STRAWBERRY.}

This absolutely unique berry is the outcome of over thirty years test of more than 5,000 varieties carried on in the North Carolina Hills, the Natural Home of the Strawberry, and where even in the wild state it attains a perfection unrivalled anywhere on the face of earth. It has been fully tested in every variety of soil and is guaranteed to thrive anywhere in the United States. We believe that it can be grown in a barrel even in the Tropics, a little shade being given in the very heat of the day.

The Never-Stop planted in garden or field will bear from earliest ispring till hard freezing winter sets in, defying ordinary autumn frost. Winter often catches it in full bearing, and you rake off the snow and gather the delicious ripe berries.

At the South it can in ordinary seasons be made to bear some fruit right on through the winter by raking a little straw on the rows in cold snaps as directed in our booklet.

100 plants, $\$ 2.50$, delivered free with booklet, makes success certain. Not less than 100 sold. 


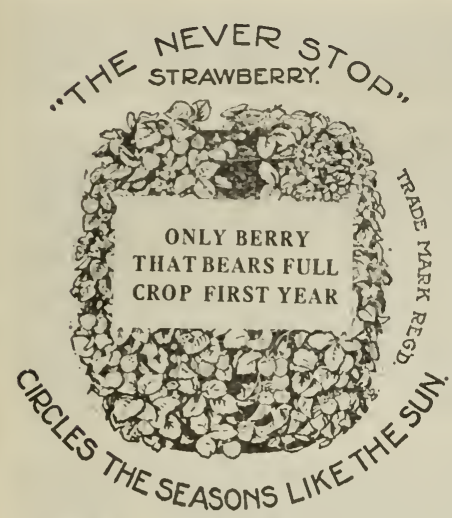

This unique variety can be grown in a barrel. Bore $1001 \frac{1}{3}$-inch holes in an ordinary whiskey or molasses barrel (box will answer) and as you fill it with rich earth set a plant in each hole. The result will be not only a good yield of large, delicious berries, but at the same time the most uniquely beautiful outdoor or indoor ornament imaginable. Any spot three feet square in front yard, garden, conservatory or greenhouse will answer provided the sun shines on it all day. All beholders will be charmed and amazed at the solid mound of leaves, blooms and berries, and at the fact that it continues to flower and fruit continuously.

At the South it will during ordinary winters fruit out-ofdoors if protected with a rug or blanket in cold snaps. Though if severe cold should come the only effect would be a temporary check to the fruiting.

At the North, if carried in sunny conservatory or greenhouse as cold weather shuts down, the barrel will fruit all winter.

Wherever the barrel stands, summer or winter, it must have the sun on it all day. Sunlight is necessary to all fruits.

Plants can be set this way at any time of the year and will at once begin to bloom and bear.

Our claim that one acre of thoroughly rich soil set in Never Stop properly cultivated will bring $\$ 2,500$ is based on the following conservative calculation: In rows three feet apart and 18 inches in the row an acre will hold 10,000 plants. Set in the fall the plants will begin to bear early in spring and at the same time to make young plants. The young plants begin to bear the first year. This old plant and its young have repeatedly borne a quart of berries from April to November. The exquisite beauty and flavor of these berries, their magnificent size and glorious flaming color and the fact that most of them ripen after all other berries are gone will sell them anywhere at 25 cents a quart to either first-class hotels or to individuals who seek the very best. Of course to bear at the above immense rate the soil must be fertile at the start and then highly manured and carefully tended, full directions for which is given in booklet accompanying each 100 plants. But even under ordinary culture Never Stop is a heavy and constant bearer of fine berries.

Never-Stop Plants are sold under the following contract: The buyer has the right to propagate all the plants he wishes for his own use but he is not allowed to sell, give away or part with any plants. (See page 8.)

Our booklet, which is free with every order for 100 plants, gives clear, concise directions for growing in garden or in barrel.

The older these plants get the more constantly they bear. We have two year old "stools" (plants from which all runners were clipped and forced to bunch) which at this writing (Oct. 20th) are simply loaded with fruit, nearly a quart to the plant. Clip all runners except enough to make about 12 young plants to each parent plant. Take a little pains and have these to root about one foot apart. Then the following two years allow no runners to grow and keep the bed clean. Good garden soil will need only one pound of fertilizer to ten yards of row worked in around these old plants each spring. Beware of over manuring especially in barrel culture or too much watering.

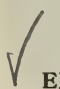

\section{EXTRA EARLY KINDS.}

EXCELSIOR-This is the standard extra-early strawberry-from Florida on the south, to Illinois on the north, from Virginia on the east, to California on the west. In fact, it is the earliest productive berry ever known. And yet frost never defeats a crop of Excelsior. For while its blooms are not frost proof, like those of the Never Stop, so great is the vigor of the Excelsior that if killed down, even when in full bloom and berry, it will at once put out anew and make nearly, if not quite, as large a crop as if nothing had happened. If that isn't your repeater, what is? Drought at fruiting time, or, as to that, at any time, has little or no effect on it. Indeed, except Improved Lady Thompson, it is nearer drought proof, frost proof and neglect proof than any other standard variety. As it thrives through more degrees of latitude and longitude than any other variety ever known, so also does it succeed on a greater diversity of soil. We have seen fields of it "turned out" neglected for years, which yet continued to bear excellent crops. Excelsior, while the earliest, most brilliant colored and best shipping berry when perfectly ripe, and no berry should be gathered for the latter until perfectly ripe, has a fine racy flavor.

\section{STRAWBERRY PLANTS SHIPPED UP TO JUNE $15 T H$.}

Always plant as early as possible. To those who cannot plant early or who live at the North where planting is necessarily done later, in April, May or even June, we can ship plants guaranteed to arrive in perfect condition. These plants are in a perfectly dormant state and will live and grow off rapidly no matter how hot and dry it is. But orders to be shipped late should be booked as early as possible. (See pages 3 and 33 ). 
VIRGINIA - Next to Excelsior and Missionary in earliness comes Virginia, a fine, firm, well shaped, well colored berry and a very heavy bearer. The only objection urged against Virginia is that it is a pistillate-an imperfect bloomer. But this is no just objection. For, by planting every fourth row in Excelsior, or by thoroughly mixing, with it one-third Excelsior and planting all together, thorough pollenization and a heavy crop of berries will result. It is a magnificent berry.

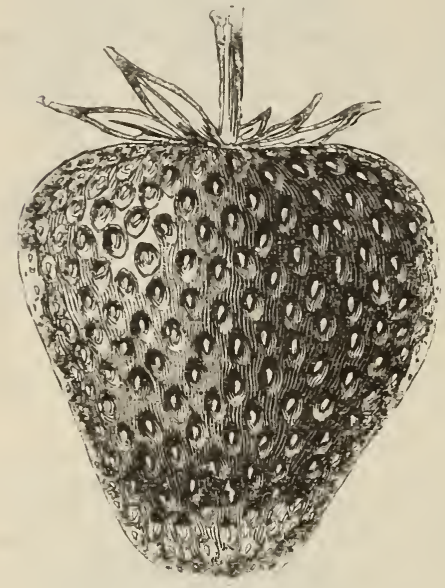

MISSIONARY. The Great Extra Early Berry that never fails "to get there"

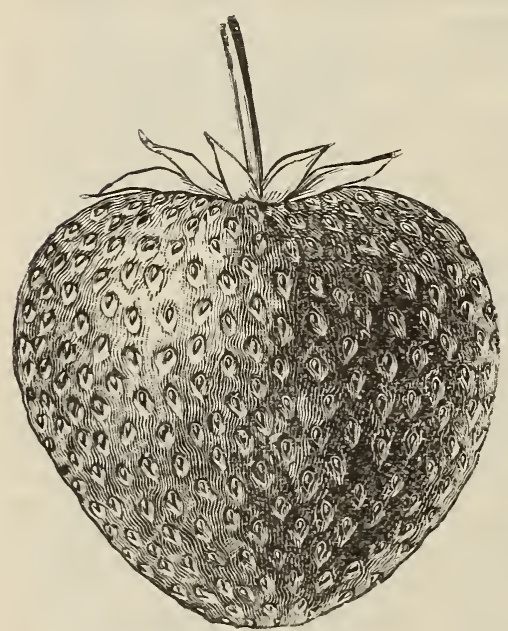

HEFLIN'S EARLY. The Apollo (Handsomest) of all Berries
MISSIONARY-Missionary holds the same place among the extra early that Lady Thompson does among the early strawberries. It never fails "to get there". If you have been disappointed in all other extra early kinds-if they were shy bearers; if they ran small, if they were too soft, too colorless or too insipidin short if they were unsuited to your soil or your needs, then plant Missionary. It will not disappoint you. Like the famous Lady Thompson it has a vigor of root and plant that enables it to thrive on all soils and climates. On poor land it does well, on rich land better. On all it bears an cnormous never failing quantity of large firm deep red berries. Missionary is no stranger. It has been fully tested through all the central and southern parts of the country Here it has been uniformly and splendidly successful. Such tests as have been made north of the Ohio River have also been successful.

HEFLIN'S EARLY-As a huge startlingly beautiful market berry Heflin is clear out of sight of everything that we know of. It is by long odds the handomest berry that grows. Its color is flaming red and its size immense. It is firm enough to ship any distance. At the South from Maryland down it is easily king of its class, capturing every market upon which it is shown. It has not been tested, as far as we know in the North or Northwest but would probably succeed there, especially on light or sandy soil and especially in alluvial soil along streams.

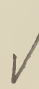

\section{EARLY KINDS.}

IMPROVED LADY THOMPSON-This is a standard table and market berry over prcatically the whole country Not because it is the very best of them all-though it is a splendid berrybut because it is the surest; because it never fails to get there, because no matter what happens, drought, heat, frost, it never misses a crop, and a whopping one. It spells success, profit. Lady Thompson is an immense bearer of large mild flavored berries that are firm enough to ship 1,000 miles. It thrives in all kinds of soils and will do well in soil that is too poor, too wet, too thirsty, for any other kind whatever.

It will also stand more neglect and still make a crop of fine berries than any other kind. If killed down while in full bloom it comes out again with a good crop. The largest yield of berries per acre in our knowledge c a me from Lady Thompson plants. It is the surest of all kinds to live when planted.

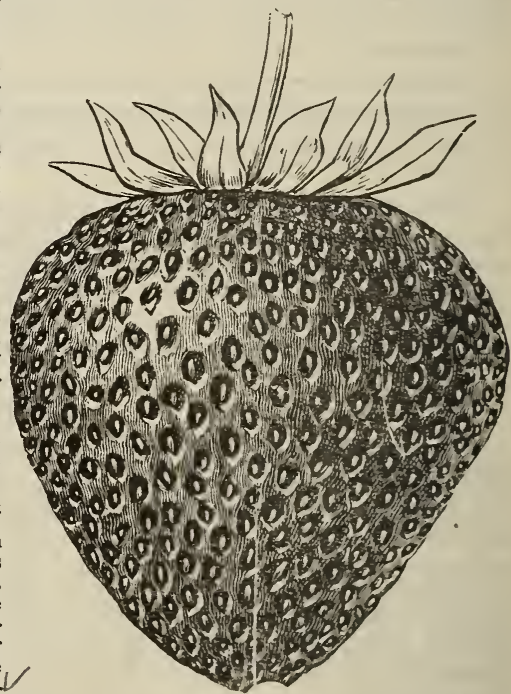

LADY THOMPSON. Standard Early Berry of the whole country. Has never failed to bear heavily, Fruited by us 25 years

\footnotetext{
KLONDIKE-This magnificent berry forms, along with Imrpoved Lady Thompson, Missionary and Excelsior, the great shipping and market quartet. The sterling points of genuine Klondike (bear in mind that there is also a spurious and comparatively worthless berry masquerading under this famous name) are great productiveness, large size brillint color and unsurpassed firmness. Like the Improved Lady Thompson, Excelsior and a few other exceedingly virile kinds. Klondike will, if killed down by frost, put out anew and still make a good crop.
} 
SENATOR DUNLOP-This is the standard berry throughout most regions of the central, westcrn and northern parts of the country. There it is the ideal berry, large, firm brilliantly colored, productive. No other variety seems to stand the hard knocks of droughty regions like the iron-clad Dunlop. To crown it all its quality and flavor is among the very best. Large growers of Dunlop berries for market get their plants every year from us rather than grow them themselves, finding that plants grown in a natural strawberry region like this give far better results than their home grown ones. Many growers of other leading varieties who live in less favored regions than ours-regions where this somewhat fastidious berry is not strictly at home-have for a long while found it better to use our plants than their own.

$\checkmark$ BRANDYWINE-A large, productive, well-flavored variety, popular for the rcason that its ripening period covers a longer time than any other variety, except, of course, the indefatigible Never Stop.

\section{MID-SEASON VARIETIES.}

HAVERLAND-A sure and enormous bearer, but the berries are too soft for anything but home use or nearby market. It has also the bad quality of producing its fruit on very short stems, requiring good mulching to keep them clean. Despite these drawbacks, and we seek to tell the bad as well as the good qualities of the plants and trees we grow, it piles up such prodigious crops of berries that many find it the most profitable of all. Imperfect bloomer. Pollenize with Klondike, Brandywine or Dunlop. See directions for the Virginia.

$\checkmark$ WARFIELD-Like Dunlop, this is suited best to the western, central and northern parts of the country. Medium size. Famous for its brilliant color and fine flavor; a flavor so popular that many noted hotels and cafes advertise that only Warfield berries are served on the tables. Imperfect bloomer. Pollenize as directed for Haverland.

\section{LATE VARIETIES.}

GANDY-A standard late berry, suited to all parts of the country. Large, productive, firm, splendidly colored. A famous table and márket berry. Tends to rust in some sections, but growers will find that plants treated with fungicide, as ours of all varieties are, will be comparatively immune from rust for at least two seasons, no matter how bad it may be in that section.

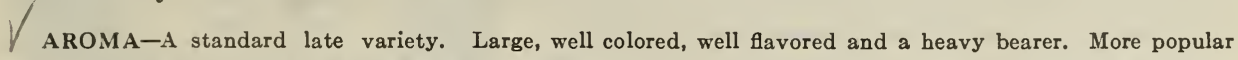
than Gandy in some regions. With us its six of one and half a dozen of the other. We never could choose between them. Plant either and you will go right. Perfect bloomer.

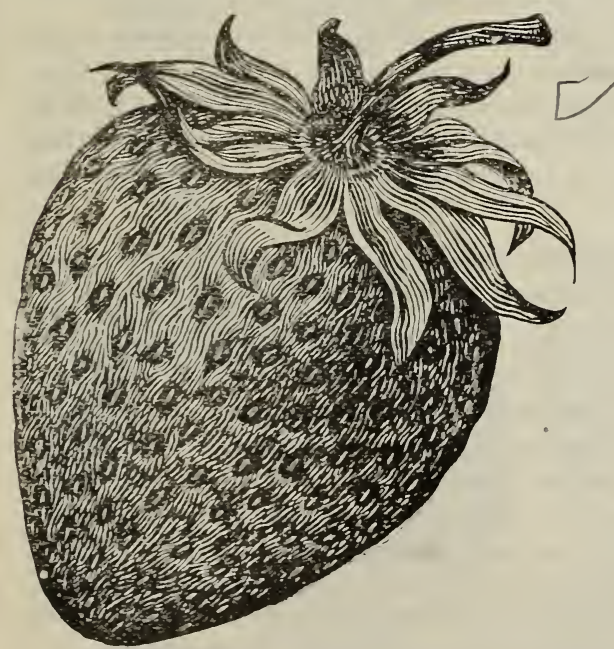

\section{THE GIANT TRIBE OF STRAWBERRIES.}

GREAT SCOTT, TIP TOP.-These are the varieties for home use and fancy market that require quality as well as looks. For this purpose they stand in a class of their own. The connoisseur, the real strawberry lover the man or woman who wishes the very best the world affords will plant one of these varieties and get his fruit from them for several weeks of spring. Meanwhile he will keep all blooms pinched off the Never Stop so as to force them to produce their whole crop later in the season. Both Tip Top and Great Scott are heavy bearers of huge brilliantly colored berries. Along with Never Stop they form the ideal kinds for home use and strictly fancy market.

GREAT SCOTT. The Ideal Spring Fancy Berry 


\section{Fruit Tree and General Nursery Department.}

\section{WE ARE PIONEERS IN SELLING DIRECT TO THE PEOPLE.}

The Lime and Sulphur Spraying Mixture (directions for supplying which can be had free from the Experiment Station of any State) has removed all danger of San Jose scale, no matter if your neighborhood should happen to be badly infested with it. This simple, inexpensive mixture keeps down pests, and in that respect makes fruit growing about as sure and safe as corn growing.

Buyers may feel absolutely safe in buying stock from us, as our trees, plants, etc., are carefully examined by the State Entomologist, then subjected to a far closer scrutiny by an expert in our own employment, and then fumigated so thoroughly that no pests could survive even if present.

HOW TO KBEP TREES TILL THEY CAN BE PLANTED.-If you are not ready to plant immediately upon arrival of the trees, open and unwrap the bundles and heel or trench them in deep enough to cover the root well, the deeper the _better. If the soil is very dry, fill the trench with water, and let it soak in before replacing the dirt around the trees, which should be carefully done, and packed firm and kept moist by occasional watering. If the trees or plants should arrive in freezing weather or chance to freeze on the way (something almost impossible with our packing), don't be at all alarmed. They are used to it where they grow in the nursery. All that is necessary is to see that they thaw gradually, and in a natural way. The best plan is to unwrap them and bury them, roots, tops and all, in moist soil, until they completely thaw. Should this be impracticable, owing to the ground being frozen, a deep burial in moist straw will answer about as well. Or if the trees can be placed unwrapped in a cool cellar and left till they thaw, no harm will result.

WHERE TO PLANT AN ORCHARD.-Orchards planted on hills, where the air is apt to be in motion at night, are much safer from frost. Besides, fruit is apt to do well on elevated, well-drained land. Land even so stony that it cannot be well used for any other purpose will make a fine orchard, and with a little attention will pay better than the pet acre on the farm planted in anything else. Still, fruit trees, like other things, do better in proportion to the richness of the soil and the thoroughness of the cultivation.

HOW TO PLANT AN ORCHARD.-Plant apple trees 30 feet apart each way, 50 to the acre. Peach, plum and apricot trees and fig bushes and scuppernong grape vines, 15 feet apart each way, 196 to the acre. Pear and cherry trees, 20 feet apart each way, 100 to the acre. Bunch grapes, 6 feet apart each way, 1,225 to the acre.

The peach and plum being quicker growing and shorter-lived trees than the apple, the following plan is good where the land is limited: In the row between each apple tree set a peach or plum tree. Also between each row of apple trees plant a row of peach or plum trees fifteen feet apart. This will give about 50 apple trees and about 150 peach or plum trees to the acre. The peach and plum trees will begin to bear at two to three years old, and will bear some five or six crops before they crowd the apple trees very much. When they do the peach and plum can be dug out, leaving a fine apple orchard.

Three rows of strawberry plants can be set between each fifteen-foot row of peach trees. Where apples are planted In thirtyfoot rows with no peach trees between, seven rows of strawberry plants can be set between.

To prepare the land for planting of fruit trees, plow thoroughly and as deep as practicable. Open the holes eighteen inches deep and two feet square. Fill the hole with top soil near enough full so that the tree on it will, when the hole is filled, be two or three inches deeper than it grew in the nursery. Spread the roots evenly, having first cut off any bruised ends. Then fill the hole, tramping the earth firmly around the tree. In filling the hole, bottom and top, use only the best top soil that can be scraped up in the orchard. Scatter the clay from the holes as far as possible from the tree. A moderate quantity of well-rotted manure and wood ashes can be used in filling the hole, but it is best not to let them come too near the roots. Always wet the roots before planting. If the soil is dry, set the tree, fill the hole nearly full of earth, and trample it around the tree. Then pour in as much water as will soak in readily, giving it full time. When it disappears, fill the hole and heap it a little with earth, but do not trample it. If trees would appear dry or shriveled when received, a few hours soaking, roots and tops, in water will restore them. 

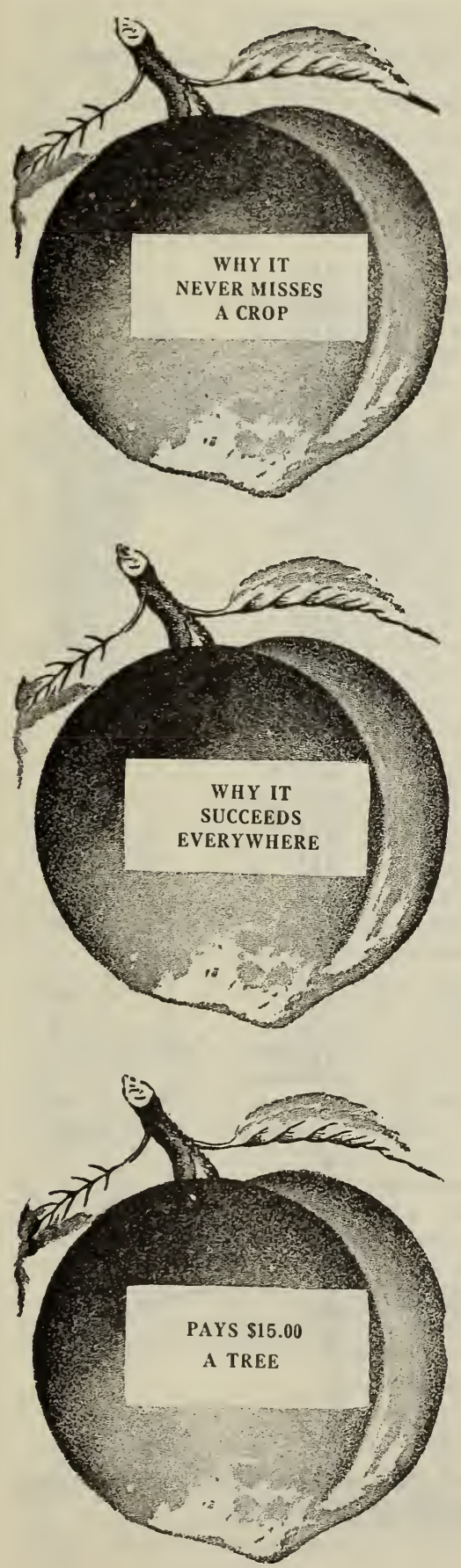

\section{The Neva-Myss.}

\section{Or Early Wonder Peach.}

It is the earliest of all peaches, ripening far ahead of any other kind.

It stands entirely outside the class of early peaches, which are small, insipid and of poor color. The Neva-Myss is a large, magnificently colored, delicious soft peach.

It has never missed a crop and a good one in the nine years we have fruited it. Ordinary kinds miss as often as they hit, or of tener. This unique trait of course adds immensely to its value to all who grow for either pleasure or profit. It is in the off years that first-class fruit pays.

There is no dark mystery in this immunity from frost. Just plain cause and effect. It just happened to belong to the type of peaches that bloom late. Again it just happened to combine with this rather rare trait the rarer trait of early ripening. The result was a variety that bloomed after the worst frosts are gone and still ripened ahead of all other kinds.

Second, it is a heavy gradual bloomer. If all blooms should be killed once or even oftener there is always enough left to make a good crop.

Third, it has in more marked degree than any other kind the habit of retaining the "shuck" or collar of the bloom a long while. This makes an excellent frost protector.

Fourth, the intense vigor of everything pertaining to this lusty variety seems to render it largely immune from frost as it does from drought and other foes.

In vigor of tree growth it is as pre-eminent as in other things. This quality not only enables it to bear the enormous crops that it does year after year instead of taking every other year off to rest as most kinds do, but it also enables it to thrive in soils and climates in which few other varieties of peaches would grow at all.

Sold in fancy local market it is paying $\$ 15$ a tree. Regular orchardists are netting $\$ 5$ a tree on large plantings. See pages 24,25 and 28 .

\section{WHAT THE NEVA-MYSS OR EARLY WONDER DID IN TEXAS.}

Two of the Early Wonder Peach trees that I ordered of you in February, 1911, have developed twenty-eight fine, luscious, commercial peaches in less than sixteen months from date trees were set out. I call that going some. These peaches are truly a wonder to all who have seen them. I am so pleased with them that I shall order more this winter. All that you say about the Early Wonder Peach (so far as my experience has gone) has proven true. I had four other varieties of peaches set out about the same time as were the Early Wonder. All bloomed this spring and most of them fruited more or less, but the Early Wonder were the only ones that held and developed their fruit. The Early Wonder was the latest of the five varieties to bloom. They are certainly beauties and get their color eight or ten days before they are ripe. You certainly cannot recommend the Early Wonder Peach too highly.

Palacios, Texas, May 30, 1912.

Yours very truly,

j. W. BELKNAP.

Neva-Myss Trees are sold with the distinct understanding that the buyer will not resell and will neither propagate nor allow any trees to be propagated from those sold him. (See page 8.) 


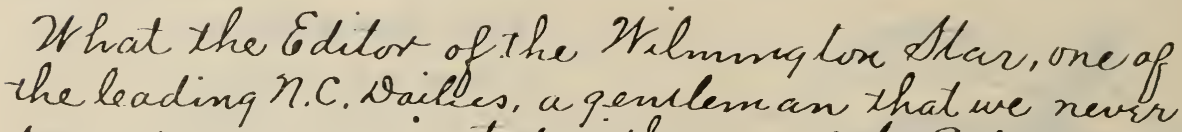
saw or communic ated with saypo of the Eanly Honder This proves that it thrives enen on hershe rast coustul region of the Routh where few Pinds will.

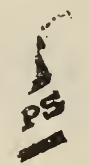

About three years ago he planted 15 peach trees of different varieties and they are all flourishing. Among them are two trees of the "Early Wonder" variety, and they bore some magnificent. peaches a year ago last May. They also produced this year, although they were cold-hurt this Spring. Nevertheless, they began to yisld fine ripe peaches in May and Mr. Toomer is

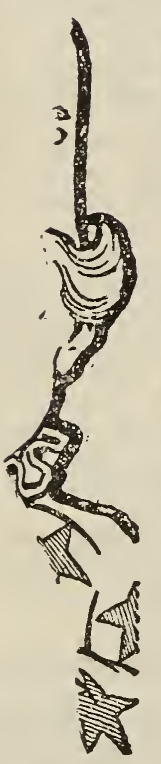
continuing to gather perfect beauties from his trees. The Star can testify that they are beanties, for Mr. Toomer brought us some fine ones yesterday. He shrank from any publicity about it Dut he says -when a country can ivroduce early peaches of such magnificent quality it ought to be made known so our people can take advantage of it. Mr. Toomer got the "Farly Wonder" from the Contineutal Plant Company, Kittrell, N. C., and to see them nearly as large as a man's first, blood-red on a bluff background, and perfectly delicious in flavor, is to raise one's conccptions of the fine possibilities of the peach-growing industry around Wilmington.

In addition to the natural beauty and superb quality of the "Farly IVon der," its chief merit is that it ripens early and is a fine shipper. It is firm and it takes on its rich color ten days before it is fully ripe, a fact which shows that when shipped it gets into

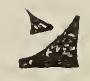
market looking like a peach and in the very best condition.

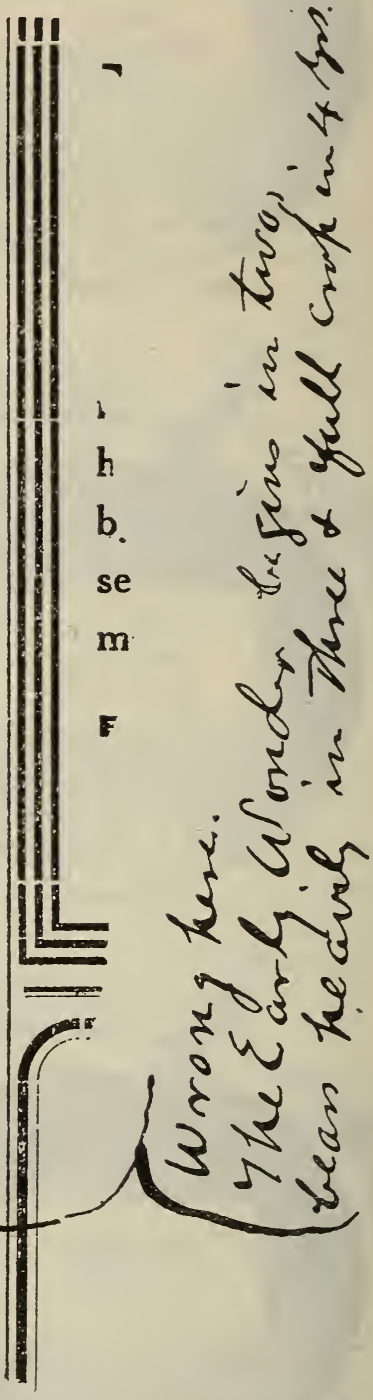

iT. comes into bearing in three years and into full bearing in five years, and we hope to live to see the day that far we eastern North Farolina will be cover rt ough+l ed with it

"ies. Prop--

For proof of the surprising earliness, magnificent size and marvellous profits from Neva-Myss in many States, or Early Wonder, see pages 24, 25 and 28. 


\section{THE EXQUISITELY FLAVORED TABLE PEACHES.}

AMBROSIA.-(Food of the gods.)-The most exquisitely delicious peach yet produced. Clear seed, soft and melting. A revelation in peach flavor. A heavy and sure bearer, ripening in July. Color beautiful cream and crimson. So delicious that it can be eaten with cream without sugar, making it wholesome for even the weakest stomach.

$\checkmark$ NIAGARA.-An immensely large, brilliantly colored, exquisitely flavored peach of the Elberta type, but much earlier and far superior to it in quality. It seems certain that Niagara will take the lead of the class of the strictly fancy peaches, for it is in size, color and productiveness not surpassed by any of them and not approached in flavor by the best of the giant peaches. July.

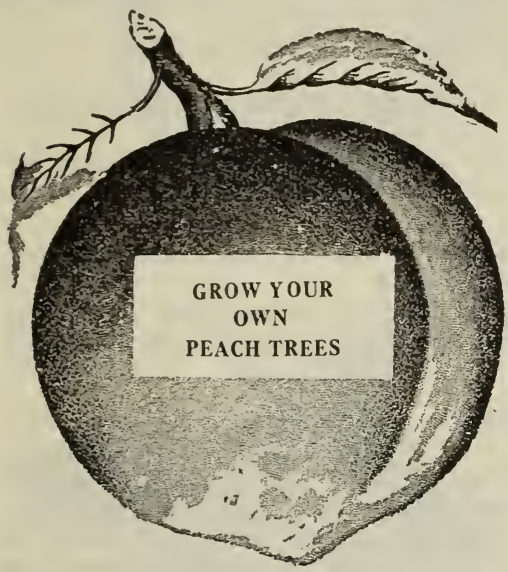

WINE PEACH.-A rarely beautiful red-cheeked, medium-sized peach of the most delicious flavor. Clear seed, soft, so luscious that it can be drank like a glass of wine, which it resembles in flavor. It has the almost unique habit of propagating true from the seed. You can grow all the trees you want by simply planting the seed. Has been grown here from seed for fifty years, and has never missed a crop. This gives a rare and distinct value to the Wine Peach. (Six trees of Neva-Myss, Ambrosia, Niagara or Wine, selected as you please, $\$ 2.50$, delivered free).

\section{EXTRA EARLY PEACHES}

SNEED. - This is recognized as one of the standard early peaches over the whole country. It follows Early Wonder closely, ripening early in June. It is of good size and is unusually productive; a fa rly well-colored peach, which is so luscious that when ripe it can be drunk like an orange.

$\checkmark$ GREENSBORO.-This is a glorious mid-June peach. In size it ranks among the very largest. Its color is an exquisite cream and crimson. Its quality is luscious and melting. Succeeds generally throughout the country and as far south as the Gulf of Mexico.

$\checkmark$ DEWEY.-This is a large, exceedingly handsome red and yellow soft peach. The trees are fine growers and heavy bearers. It is one of the few really fine varieties that succeeds generally throughout the country and in Florida, where it thrives well, except in the extreme southern part. Follows Sneed closely in time of ripening.

\section{EARLY PEACHES.}

CARMAN.-A very large brilliant red peach of excellent quality and immense productiveness. Soft and nearly freestone when ripe. Equally good for home and market, being firm and a fine shipper. Does splendidly throughout the country clear down to the Gulf of Mexico. Ripens in June.

BELLE OF GEORGIA.-Another of the great cream and crimson peaches. An exceedingly showy peach and a good one, too. An excellent shipper, firm and a good carrier, though a freestone, and soft and luscious when thoroughly ripe. Succeeds generally throughout the country down to the Gulf. Early in July.

BURKE.-A mammoth, superb white and red peach, of showy appearance and good quality. Late July and early August. Clingstone.

CHINESE CLING.-A large white peach shaded with red; fine quality. Last of July.

STONEWALL JACKSON CLING.-Similar to Chinese Cling, of which it is a seedling, but a decided improvement on it. A really magnificent peach. Last of July.

\section{MIDSUMMER PEACHES.}

ELBERTA.-Easily king of its ripening season. A mammoth gold and crimson peach of excellent flavor. Famous for its vigorous growth, immense productiveness and adaptiveness to all soils and climates. Great for home use, for market, and for all purposes. Thrives generally and even as far south as Florida. Freestone. August the 1st. Caution: There are two, if not three or four varieties, differing greatly in merit, called Elberta. We have the genuine Elberta, on which so many millions have been made by the Georgia growers. 
NEW PROLIFIC. - Similar to Elberta, and one week later. Valuable to keep up the succession of peaches. Freestone.

$\checkmark$ GLOBE.-A very large, soft, clear seed peach of excellent quality. Early August.

CRAWFORD'S LATE.-Another splendid red and yellow peach. A shade later in ripening than Globe. Freestone. Does well even as far south as Florida.

STONEWALL JACKSON'S FREE.-Said to have originated from a seed brought by a Confederate soldier from the Gettysburg campaign in 1863. A giant gold and crimson peach of excellent quality. Noted as being a sure bearer. Valuable. Latter part of August.

$\checkmark$ OLD MIXON FREE.-A large, white and red soft peach of fine quality. Late August.

MATTHEW'S BEAUTY.-Another excellent red and yellow peach. Last of August. Freestone.

\section{FALL PEACHES.}

WHITE HEATH.-A large, white clingstone peach of excellent eating, canning, preserving and selling qualities. First half of September.

$\checkmark$ EATON'S GOLD. - A very large, finely flavored gold and crimson peach. Valuable for all purposes. Said to have originated here from seed sent from Japan before the war, about 1855. Last half September. Clingstone.

ALBRIGHT'S OCTOBER.-A large, white, well-flavored peach for any season, doubly valuable because it ripens so late. First half October. Clingstone.

$\checkmark$ STINSON'S OCTOBER.-A large, red peach of good qualities-if anything even later than Albright's. These varieties are often kept till Christmas, and sometimes called winter peaches. Clingstone.

\section{The Japan Plum.}

This is not only one of the most beautiful and delicious, but also one of the most wholesome of fruits that grow. All of the varieties are large, and some as large as good-sized apples. They are really a revelation in plums. They succeed generally, and are about the easiest of all fruits to bear, and the crops they yield are enormous. These superb plums have none of the unwholesomeness of our wild plums. They are the most wholesome fruit that grows, more so even than the peach-invalids even and young children eat these with positive benefit. Once in bearing-and they bear well from two years old up-and you would not take $\$ 25$ a tree for them.

RED JUNE.-The earliest of the Japan group of plums, ripening in June. Size very large, color flaming red, quality very good. A sure and exceedingly heavy bearer. Valuable for home use or market on account of its earliness, beauty and general excellence.

CLIMAX.-A cross between the Japan and our native plums, originated by Luther Burbank. Climax ripens soon after Red June. In size, in magnificent coloring, in enormous, amazing productiveness, and in exquisite flavor, it ranks with the best.

ABUNDANCE.-Very large and of indescribable beauty. Closely follows Red June in ripening, and remains in bearing a long time. Rightly named for its immense productiveness Quality probably equal to any fruit that grows. Begins to bear on good soil at two years old, and rarely or never fails to produce a large crop of the finest fruit.

$\checkmark$ WICKSON.-Cross between the Japan and our native plum. Noted also for the beauty of its tree growth and fruit, and for the excellence of its immense crop of fruit. Ripens soon after Abundance.

APPLE PLUM.-Resembles an apple in appearance. A very large plum of excellent flavor, ripening in July.

HALE.-A very large and yellow plum, with a peach flavor. Early August.

$\checkmark$ СНАВОт.-Another large, red and yellow plum of good quality, ripening in late August.

$\checkmark$ WILD GOOSE.-A large, purple-red plum of native origin. Well-known for its productiveness and good-eating qualities. Early June.

$\checkmark$ EARLY GOLDEN APRICOT.-A very fine, deep yellow apricot.

$\checkmark$ SHROPSHIRE DAMSON.-The finest and most productive of all the damson family. Grown chiefly for preserving, for which it is unequalled. 

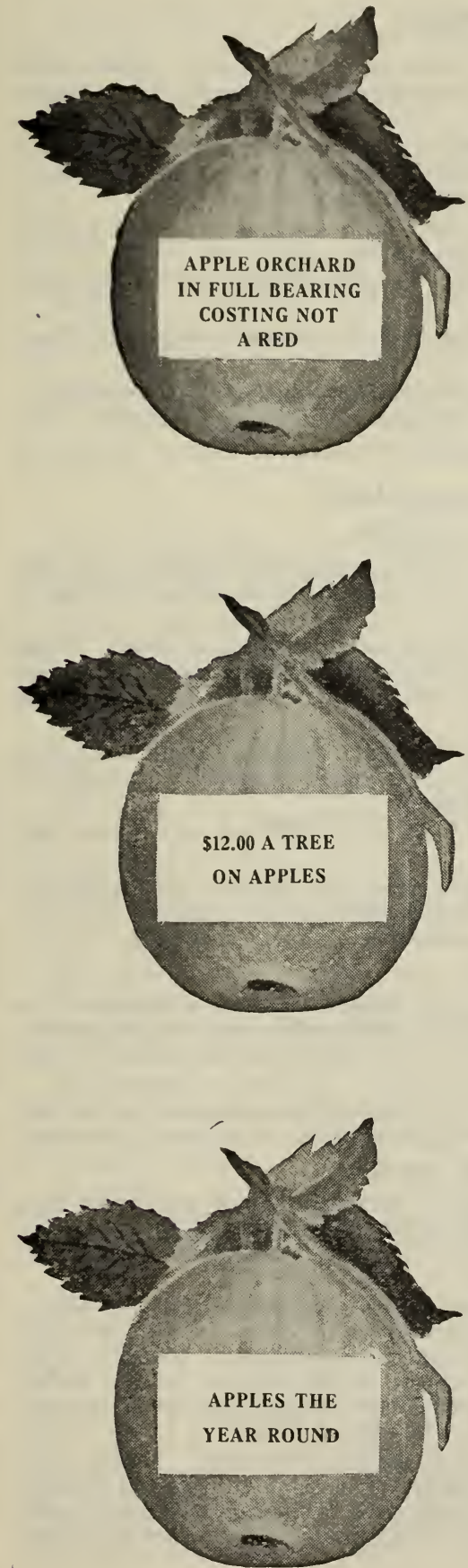

Apple Trees.

Grown in the Hills and in the Natural Soil of the Apple. (See page 4.)

The apple is both food and medicine. Science tells us that most disease is the result of accumulation of toxic poison in the system and that the malic acid of the apple is the most potent known agent in counteracting and expelling this poison. An apple eater is almost sure to be free from rhemuatism, gout, kidney, liver and stomach troubles. $\mathrm{He}$ is rarely or never glutton, drunkard or doper. He has red blood in his veins; a head on his shoulders. He counts.

The average person especially the average child needs apples, plenty of apples. "That's so," roars the "Old Man." "But its cheaper to buy apples than to grow them." But find me the one that does; or the family that has plenty of apples at any time of the year unless they are grown at home.

Again, that it is cheaper to buy apples than to grow them is like divers other of "The Old Man's" axioms, fudge, pure fudge and bluster. In fact an apple orchard can be planted and brought into full bearing and not cost a red. Plant peaches between the apples and strawberries between the peaches as outlined on page 14 and described in full in our Manual. The strawberries will come into full bearing the second year or if Never Stop is planted the first year, pay all expenses incurred for trees, plants, cultivation and leave a handsome profit besides. This they will repeat for three years. By then the peaches will come in and do likewise. The apples will come into bearing the fourth year, into heavy bearing by the seventh, and full bearing by the tenth year. The peach can now be cut out leaving a fine apple orchard bearing annually two barrels to the tree, which instead of costing has been putting money in your pocket from the first jump.

Apples cost here (and this is an average community) never less than 50 cents a peck or at the rate of $\$ 6.00$ a barrel. At that rate an orchard would every year be worth to you $\$ 12.00$ a tree or $\$ 600$ an acre.

Therefore let "The Old Man" shut his mouth, open his heart and plant apple trees. By planting varieties that ripen in succession you can have apples from the trees from May to November. Then by having plenty of Fall Ambrosia, Dixie, Winesap, Stayman, York Imperial, etc., gathering and storing them in a cool dry cellar or in sand anywhere, the family can enjoy this beneficent fruit till the spring brings it back again. A thrifty apple orchard well started is then proof to San Jose scale and other dangerous diseases and pests. 


\title{
Apple Aristocracy.
}

The following are the creme de la creme (cream of the cream) of appledom, which thirty years tests have enabled us to select and offer to discriminating people as the very best varieties fo the great apple family.

SUMMER AMBROSIA.-A medium size, golden flecked, red apple of the most excellent flavor. Till you have eaten one of these strains of Ambrosia you can have no idea of what a really tip-top apple can be. Ripens in August, when apples are scarce.

FALL AMBROSIA.-Superior in flavor even to the Early Ambrosia; that is, if such a thing is possible. Very large, brilliant red. Ripens in fall and keeps all winter.

$\checkmark$ DIXIE.-A superb fall and winter apple for the South. Originated there and will therefore succeed much farther south than any other apple.

ELLIS EVER BEARING.-An excellent, large, yellow apple that ripens continuously from June to September.

EARLY COLTON.- Valuable because it ripens far ahead of all other apples of any value. A large, handsome, well flavored apple, ripening in early June into a veritable ball of gold.

HUNT EVER BEARING.-A medium sized apple of most delicious flavor; ripening all through June, July and August.

Six trees of any of above six kinds, $\$ 2.50$, delivered free anywhere.

\begin{abstract}
SPRING AND SUMMER APPLES.
YELLOW TRANSPARENT.-This is a very fine apple indeed, good quality, good size, beautiful, with a yellow tint, a sure and heavy bearer. A really delicious apple. Ripens in
\end{abstract} June.

$\checkmark$ RED JUNE.-Famous for its striking beauty and also for its sprightliness of flavor. With a coat of flaming red and meat of purest white, it is one of the best known and the most popular of apples. A good bearer, and though only of medium size, a very valuable apple for home use or to sell. Ripens in June, as its name shows.

EARLY HARVEST.-A widely known standard early apple, valuable for its large size, excellent flavor, and is a sure and heavy bearer. Fruit, pale yellow streaked with dull red. Time of ripening, June. Early Harvest is universally popular.

EARLY STRAWBERRY.- Similar to the Summer Rose in quality and appearance, and perhaps even superior in it to beauty. Ripens in July.

HORSE.-A large, old apple, famous for its fitness for cider, pies, drying, and for all culinary purposes. When allowed to mellow to deepest gold it is a delicious eating apple. We have the genuine old-time Horse apple of our daddies and granddaddies. Ripens in August.

\section{FALL APPLES.}

MAGNUM BONUM.-(Great Good)-The standard fall apple. Famous everywhere for its immense productiveness and unequaled flavor. Really a most excellent and valuable apple. In size it is medium, and in looks nothing extraordinary, but its quality leaves nothing to ask for. King of its season, which is late September.

$\checkmark$ GRIMES' GOLDEN.-A large, golden-yellow apple of exquisite flavor, ripening in October. A heavy bearer, and in all respects an apple of genuine value, and of the very best of its season.

\section{LATE FALL AND WINTER APPLES.}

It is these splendid varieties and their ability to keep all winter till apples come again that gives the apple its boundless popularity and makes it the great food staple that it is, scarcely less indispensable than bread itself. These varieties thrive generally throughout the country, and are, unless otherwise stated, immensely productive in all soils and climates.

WINESAP.-Named for its delicious, sprightly, winey flavor. A standard fall and winter apple, universally popular, known to everybody and liked by everybody. In fact, Winesap has everything in its favor-name, flavor, appearance, and productiveness. Winesap is an immense and never-failing bearer of large, flaming red apples, which color up months before they ripen, making the tree a most striking and ornamental sight through the whole summer and fall. No one can go amiss when he plants Winesap. It keeps all winter.

$\checkmark$ STAYMAN WINESAP.-A seedling of the famous old standard Winesap. Similar to it in many respects. A heavy and sure bearer and a fine keeper. Thrives in all soils and climates like Winesap. Every orchard should contain some Stayman trees. The fine flavor and beautiful appearance of this apple make it, a good seller, and no variey could surpass it for home use. Keeps till apples come again. 
YORK IMPERIAL (called also Johnson's Fine Winter).-A very large, round, flattish, whitish apple, speckled with red. Meat yellowish and of excellent flavor. Keeps till apples come again.

MAMMOTH BLACK TWIG (called also Arkansas Black).-Said to be a seedling of Winesap, which it resembles in appearance and flavor. A very large, Blackish-red apple of firstrate flavor. Ranks with those fall kings, Winesap, Stayman and York Imperial, as surpassing all others as they do in the few great essentials of a first-class fall and winter apple Productiveness, flavor, beauty and "keepingness," if we may be allowed to coin a much-needed word.

RED LIMBERTWIG.-A very large, pale-yellow apple, speckled with red. Flavor rich. juicy and equal to the very best. A very fine apple, keeping all winter.

YATES.-A small, red winter apple, famous as a keeper and for its most delicious flavor.

BISMARCK.-Tree dwarfish and noted for the earliness at which it comes into bearing. Fruit of fine flavor, large and strikingly beautiful. A magnificent October apple.

SIBERIAN CRAB.-Grows in clusters with long stems. Makes the best and most beautiful of preserves.

\section{Our Pear Trees.}

\section{See Pages 33 and 34 for Price-List.}

Pears do well with or without cultivation. Some think they do best entirely without cul tivation after the first year or two. The magnificent Keiffer pear certainly thrives well in the hardest yard or lot, along fences and garden walks.

EARLY HARVEST.-A large, yellow, pink-cheeked pear of good quality. An exceedingly handsome variety in both tree and fruit. Ripens early in June. The extreme earliness, far ahead of all other kinds, gives it a high value for home use and for market.

$\checkmark$ KOONCE.-Similar to the early Harvest. A very fine pear, ripening in June.

EARLY GREEN SUGAR.-A small green pear of excellent flavor. Very productive, and said never to fail. July.

BARTLETT.-A magnificent, large, yellow pear, rich and juicy. Easily king of all August pears. A variety of very high value indeed that should be planted in every orchard.

SECKEL.-A small, brown, russet-red pear, popular for its sweet flavor. Late August.

$\checkmark$ JAPAN GOLDEN RUSSET. WILDER'S EARLY. Two other fine pears.

LE CONTE.-Strikingly beautiful in tree and fruit. Immensely productive of very large, yellow pears of fine quality. September. Most universally successful of all pears, except Keiffer.

GARBER.-Of Oriental origin like Le Conte and Keiffer, and, like them, amazingly productive. A large yellow, pink-cheeked pear of excellent flavor, rich, juicy and luscious. Late September.

$\checkmark$ KEIFFER.-The largest, handsomest and most productive of all pears. A huge lump of gold, brilliantly tinted with red when ripe. Ripens in late October and November and keeps well all winter. Trees easy to live, quick to grow off, and early to bear. We know single trees of Keiffer that bear over ten bushels year after year without ever failing. Good quality when ripe. This superb fruit, the king of all late pears, has been discovered to have one immense advantage over all other pears, and indeed of most other fruit-the tree is proof against the San José scale.

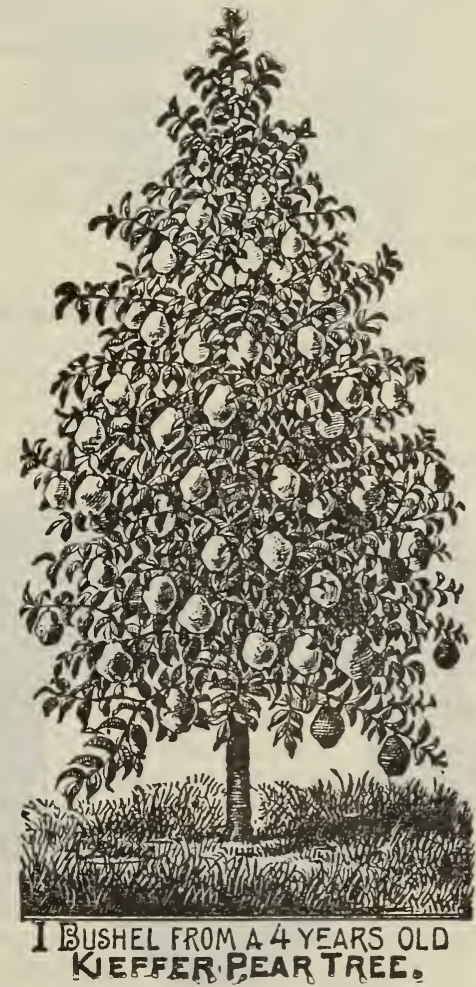




\section{Cherry Trees.}

Few trees combine the useful and the ornamental in as large degree as the cherry. They make an exceedingly handsome shade tree, worthy of a place in every yard or lawn. Or they can be grown in any spare or waste space or corner, no matter how rough and stony, needing no cultivation after the first two or three years, and they are very long-lived.

$\checkmark$ EARLY PURPLE.-A large, luscious cherry, rich purple in color. Ripens here at the very first of May with the earliest strawberries. Its fine flavor makes it valuable for home use and its size and earliness for market.

BLACK TARTARIAN.-Another splendid, large, black cherry, of same habitat as Early Purple. Ripens in May. A standard cherry, most uniformly successful of all.

$\checkmark$ GOV. WOOD.-A very handsome, large, yellow cherry of sweet, delicious flavor.

SHORT-STEM MAY.-An old standard variety, whose fine quality and unsurpassed productiveness makes it immensely popular.

$\checkmark$ ROCKPORT.-A very fine red cherry of first-rate quality, belonging to the same class as the preceding varieties.

MAY DUKE.-A very fine, large, dark red cherry that succeeds and bears heavily over a wide region.

EARLY RICHMOND.-A fine, large cherry of brilliant red color.

ENGLISH MORELLO.-An improvement on the popular Old Morello.

\section{Everbearing Mulberry Trees.}

These trees are exceedingly rapid growers, and come into heavy bearing in three or four years. Then for months they continue to ripen large quantities of fine, large fruit good to eat and of the highest value for poultry and hogs, which can be penned around trees and kept fat and healthy. No raisers of chickens or poultry of any kind can afford to be without them if they cost $\$ 5$ a tree.

\section{DEWBERRIES.}

LUCRETIA.-This is the standard variety, a sure and heavy bearer. Plants of other kinds can be supplied.

\section{BLACKBERRIES.}

EARLY HARVEST.-An early, heavy-bearing kind, universally popular, and good for table or market. Plants of other kinds can be supplied.

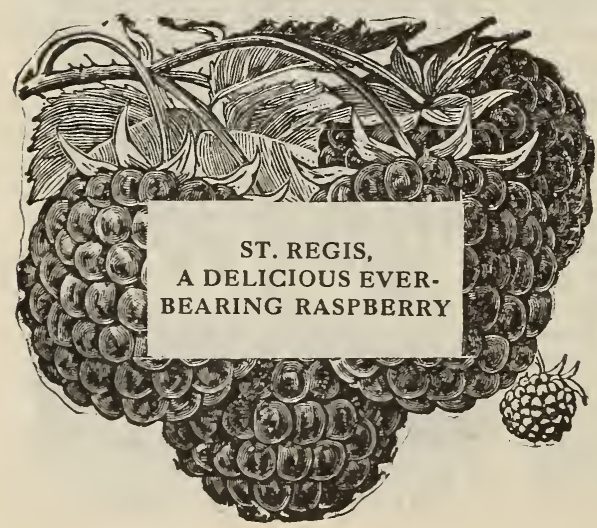

RASPBERRIES.

$\checkmark$ ST. REGIS.-This superb ever bearing Raspberry yields an immense crop of large, luscious fruit from June to October. $\$ 6.00$ per 100 ; $\$ 1.50$ per dozen.

CUTHBERT, OHIO.-We find these two raspberries to be the universally successful and popular, being heavy bearers and of good quality. Plants of other kinds can be supplied.

$\checkmark$ JAPAN WALNUT.-A beautiful quick-growing tree that makes an excellent nut. Valuable to plant in yards for shade or in larger quantities. Special low price on large quantity. 


\section{Grapes.}

SCUPPERNONG GRAPES. - The most wonderful of all the grape family. In lusciousness of flavor not surpassed, and hardly equaled by any grape or fruit that grows. Immensely prolific, and needing no attention after the first two or three years except to provide a frame or "arbor" for the rapidly spreading vines to grow on and be supported. There is scarcely any limit to the age to which it lives, or to the quantity of grapes a vine will bear.

JAMES GRAPE.-A black Scuppernong, but larger, and by some considered even more luscious and better in all respects. Similar in growth and fully as heavy a bearer. As good for wine as for the table.

\section{Bunch Grape Vines.}

The grape vines take up such little room and yield such a heavy crop of the most delicious and wholesome fruit that no garden should be without them. They can be planted along the fence or on each side of the garden walk. If so planted and trained over the walk in a trellis they bear heavily, the bunches of grapes completely roofing the leafy arch.

The bunch grape is noted the world over, not only for its deliciousness, but also for its wholesomeness. People who can eat no other fruit, except perhaps the peach and Never Stop Strawberry, eat grapes, not only without harm, but of ten with benefit to their health. In fact, the grape cure is a well-recognized system of dietics in some countries. MOORE'S EARLY. - A large, dark purple, very early grape of excellent quality. In fact, we find it to be the very earliest, good and reliable grape that we have ever seen; prolific bearer; succeeds everywhere.

$\checkmark$ CONCORD.-A fine, purple grape, closely following Moore's early, and giving a succession of grapes for a long while. Concord is an immense bearer of most excellent and wholesome fruit. Great also for wine. A standard grape everywhere.

DELAWARE. - A smaller red grape, but borne in large bunches. Famous for its delicate flavor and as a dessert grape.
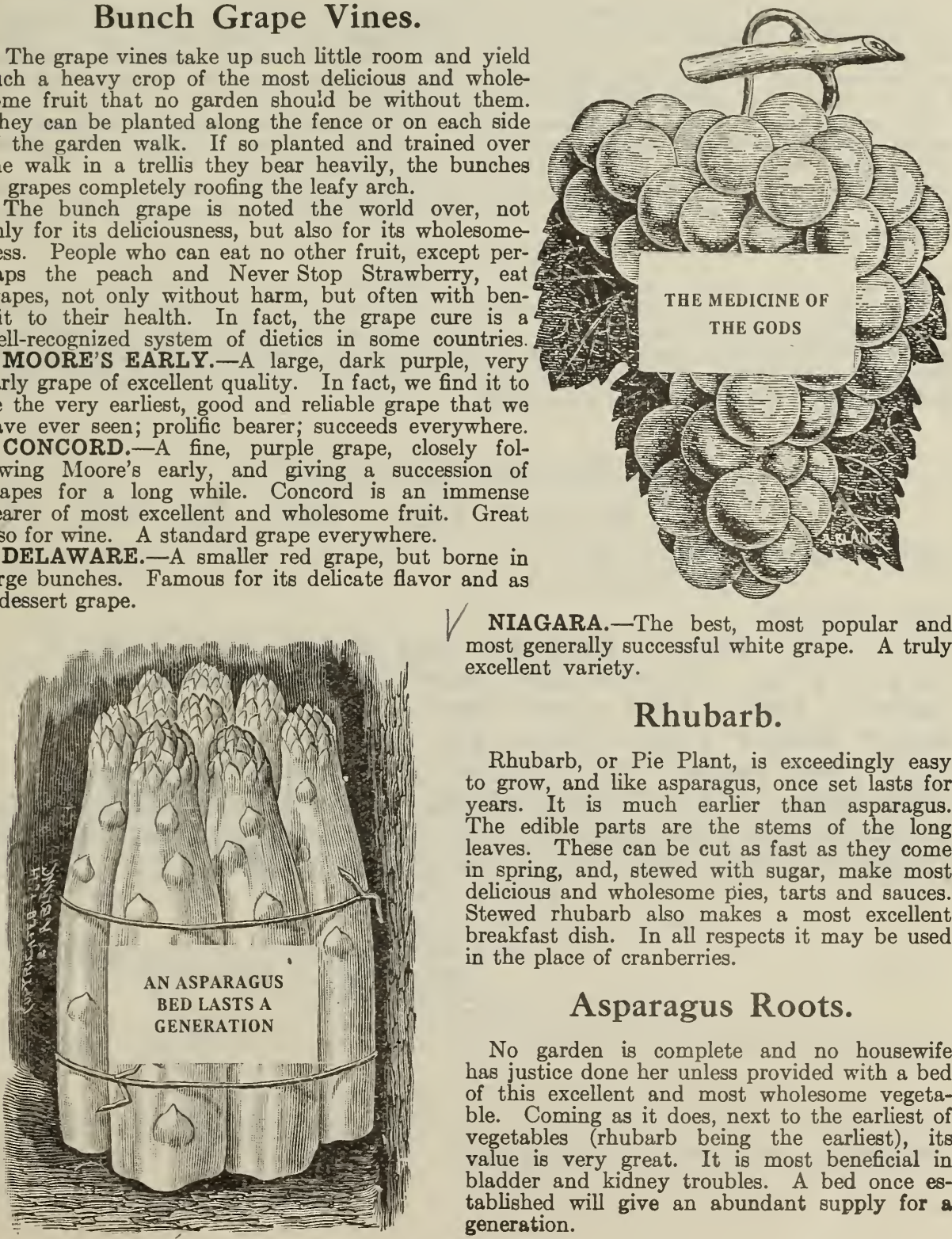

V NIAGARA.-The best, most popular and most generally successful white grape. A truly excellent variety.

\section{Rhubarb.}

Rhubarb, or Pie Plant, is exceedingly easy to grow, and like asparagus, once set lasts for years. It is much earlier than asparagus. The edible parts are the stems of the long leaves. These can be cut as fast as they come in spring, and, stewed with sugar, make most delicious and wholesome pies, tarts and sauces. Stewed rhubarb also makes a most excellent breakfast dish. In all respects it may be used in the place of cranberries.

\section{Asparagus Roots.}

No garden is complete and no housewife has justice done her unless provided with a bed of this excellent and most wholesome vegetable. Coming as it does, next to the earliest of vegetables (rhubarb being the earliest), its value is very great. It is most beneficial in bladder and kidney troubles. A bed once established will give an abundant supply for a generation. 


\section{Horseradish.}

It is easy to grow as a weed, and every good housewife knows its great value in the making of sauces and seasonings. Once used in pickle it will never be gone without. Horseradish sauce is one of the chief appetizers of the golden old-time Southern cuisine. It is also one of the few sauces or condiments that is pronounced by the best authority to be perfectly wholesome. A dozen plants will supply a large family for a lifetime, and it grows and multiplies very fast.

\section{Fig Bushes.}

This luscious and mildly laxative fruit, old almost as time itself-the fruit that refreshed and nourished the men who made history in Bible days, is about the easiest of all to grow. After the first year or two it needs no further attention unless you are far enough north for the branches to be winter killed. With a few cedar or pine bushes stacked around it as cold weather sets in it can be fruited much farther north than is usually believed. In the southern and central parts of the country (except in the mountainous portions of the central parts where it will need protection) it thrives without attention, growing into ten foot trees and producing amazingly its delicious and wholesome fruit-ten bushels to the tree has been known.

No southern home is half complete without its fig bushes and scuppernong vines. We grow the Brown Turkey fig, which we find to thrive and bear heavily over a wider range of country than any other kind.

\section{Pecan Trees.}

The pecan is the coming nut of the country, No shadow of doubt ahout that. Trees of the hest varieties come in to bearing about as apple trees do. We have trees five years old bearing nuts of enormous size freely. A grove of these would pay bigger and surer dividends than a South Africa gold mine. We supply both the large paper shell varieties and the seedlings, which are good bearers but their nuts are not so large.

\section{$\$ 1,400$ From One Acre.}

Continental Plant Co.

Bristo1, Tenn., Oct., 27, 1913.

Gentlemen:Kittrell, N. C.

When I send you the order mentioned, I am going to try your Everbearing Strawberry with barrel. About four years ago I bought of you 196 Early Wonder Peach Trees and planted one acre. This past season 700 crates of Peaches were sold from same at $\$ 2.00$ per crate, amounting to $\$ 1400.00$. It would do you good to see this acre and photograph of same. You would be proud of $1 t$.
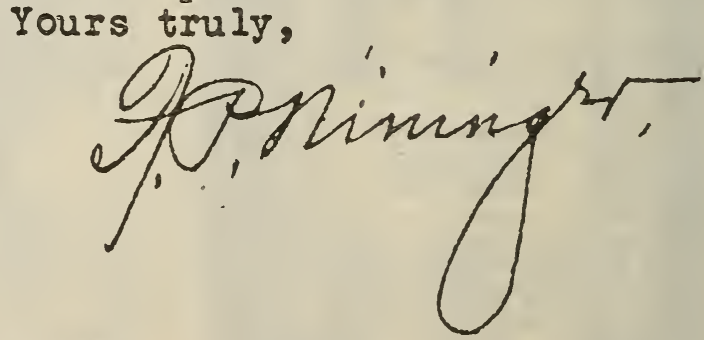

See page 25 for eight years history of this marvelous peach. 


\section{THE FOLLOWING COLLECTION OF TREES, PLANTS, ETC., DELIVERED FREE ANYWHERE EAST OF MISSISSIPPI RIVER.}

The same collections are shipped west of the Misslssippl at the following prices: $\$ 5.00$ Collection $\$ 6.00$; $\$ 2.50$ Collection $\$ 3.00 ; \$ 1.75$ Collection $\$ 2.10$. All Items "De Luxe" are delivered anywhere at prices given.

These trees are large, well-rooted, well-grown stock. They are guaranteed to be equal to the highest class trees or plants sold by any one. The reason that the prices are lower is because we sell direct to the people, thus saving them the profits of peddlers, agents and dealers.

Each collection is made up of the best varieties and of those which ripen in succession, so as to grow fruit for the longest possible season. If any variety listed should happen to be sold out, we reserve the privilege of substituting others as good.

See page 14 for directions for planting fruit trees with strawberry plants set between. The month in parenthesis shows when each variety ripens.

\section{HOW TO GET ANY COLLECTION FREE.}

Get up a club all at one time, or at different times during the same season, for any five of the following collections, and we will give you and deliver free a collection of that kind:

\section{Collections "De Luxe."}

\section{(See page 8 for only conditions upon which Never Stop and Neva-Myss are sold.)}

Unless otherwise instructed we cut back all peaches in collections to just the right height to make a perfect tree. We can do this only with trees in collections, but buyers will thus find a valuable guide to cutting back or topping other peach trees they plant.

COLLECTIONS UNIQUE (\$2.50, delivered free anywhere). 100 Never Stop EverBearing Strawberry Plants. These, under high culture, will supply average family from earliest spring till dead of winter with the most delicious fruit in existence. The only strawberry that bears a heavy crop the year of planting, beginning to bear as soon as planted, no matter what season.

COLLECTION WONDERFUL.-(\$2.50, delivered free anywhere). Six Neva-Myss (or Early Wonder) Peach Trees, the earliest peach known and the only one that never misses a crop. Large, brilliantly colored; tree growth so vigorous that it thrives and bears heavily even in regions where most varieties fail entirely.

COLLECTION ROYAL (\$5.00, delivered free anywhere). 100 Never Stop Strawberry Plants, six Neva-Myss Peach Trees, two Ambrosia Peach Trees, two Summer Ambrosia Apple Trees, two Dixie Apple Trees.

COLLECTION IMPERIAL (\$10.00, delivered free anywhere). 100 Never Stop Strawberry Plants, six Neva-Myss Peach Trees, six Ambrosia Peach Trees, six Summer Ambrosia Apple Trees, six Fall Ambrosia Apple Trees, six Dixie Apple Trees.

(See page 26.)

RATHER HAVE FIVE ACRES OF EARLY WONDER (NEVA-MYSS) THAN SKY SCRAPER IN NEW YORK.

You ask me what I think of Early Wonder peach. It is a great peach, as good as the best, a sure bearer, and ripens BEFORE all other kinds. But the greatest feature of the Early Wonder peach is its shipping qualities; in fact, it is the only early peach that I ever saw that would bear shipping a long distance. I am an old man 67 years old, was raised in Missouri, a good fruit State, and have had some experience with fruits of all kinds, but the Early Wonder peach is a wonder without a doubt, as it is large, blood red, and looks like it is dead ripe from eight to ten days before it is soft or fit to eat, so you see that makes them ahead of all early peaches as shippers. If I had five acres bearing Early Wonder peaches I would not trade it for a sky scraper in the heart of New York City.

Alcom County, Miss., Feb. 13, 1910.

Very truly yours.

H. C. MACCOUN.

\section{NEVA-MYSS (OR EARLY WONDER) PAYS \$15 A TREE.}

We had no peaches here last year except on Early Wonder. The fruit on my three trees brought $\$ 45$.

Corinth, Miss., Mch. 25, 1912.

H. C. MACCOUN.

FRUITED IT EIGHT YEARS-NEVER MISSED.

I have now fruited Neva-Myss or Early Wonder eight years, and it has never failed to bear a big crop of fruit every year an $\rfloor$ It is the earliest and best peach-in existence. You could safely insure to every man money back if it failed to bear every year.

Corinth, Miss., Nov. 3, 1913. H. C. MACCOUN.

I ordered thirty-odd trees from you last year. Every tree lived. I ordered some Early Wonder peach trees from you two or three (two) years ago. I sold the fruit this year at $\$ 5.00$ a bushel.

Chester County, S. C.. December 2, 1910.

E. P. CHANEY. 
COLLECTION A - (85, Delivered Free, 25 FIRSTCLASS APPLE TREES, choicest early, medium and late varieties. Will plant three-fourths of an acre, and peach or plum (see page 14) and strawberry plants can be set between:

2 Early Colton (May).

2 Yellow Transparent

2 Magnum Bonum (Oct.)

2 Red June (June).

2 Early, Harvest (late June).

1 Summer A mbrosia (Aug).

2 Grimes' Golden (Sept.)

2 York Imperial (fall and winter).

4 Winesap (fall and winter) 4 Stayman (fall and wint.)

1 Dixie (fall and winter).

1 Ellis (ever bearing).

Also our 100-page Fruit Manual, if asked for.

COLLECTION B.-(\$5, Delivered Free.) 25 FIRST CLASS PEACH TREES, choisesi early, medium and late varieties. Will plant one-fourth of an acre, and strawberry plants can be set between:

2 Neva-Myss (May).

2 Sneed (Early June)

2 Dewey (mid-June).

2 Greensboro (June).

1 Ambrosia (July).

2 Carmen (mid-July).

2 Belle of Georgia (late July).

2 Burk (late July).

2 Elberta (Early August).

2 Crawford's late (Late Au-

2 Eust). tember).

2 White Heath (late September).

2 Stinson's October (Oct).

Also our 100-page Fruit Manual, if asked for.

COLLECTION C.-(\$5, Delivered Free.) First-class Apple, Peach, Pear and Plum Trees. Will plant about onefifth of an acre, and strawberry plants can be set between: (See page 14.)

\section{APPLE TREES:}

1 Early Colton (May)

1 Early Harvest (late June).

1 Magnum Bonum (Oct).

2 Winesap (fall and winter).

2 York Imperial (fall and winter).

2 Mammoth Black Twig (fall 1 Stinson's October (Oct.) and winter).

1 Dixie (fall and winter).

\section{PEAR TREES:}

1 Early Harvest (June).

1 Kieffer (October).

\section{PLUM TREES:}

1 Climax (June).

1 Abundance (July).

Also our 100-page Fruit Manual, if asked for.

COLLECTION D-(\$5, Delivered Free.) First-class Apple, Peach, Pear and Plum Trees, Grapevines and Strawberry Plants:

\section{APPLE TREES:}

1 Early Colton (May).

1 Early Harvest (June).

1 Magnum Bonum (Oct.)

1 Stayman (fall and winter).

1 Winesap (fall and winter). 6 PEACH TREES:

1 Early Wonder (May).

1 G eensboro (June).

1 Carman (July).

1 Ambrosia (July).

Elberta (August).

1 Eaton's Gold (Sept). 1 PEAR TREE:

1 Keiffer (October).

\section{STRAWBERRY} PLANTS:

50 Gandy (late)

100 Excelsior (very early)

100 Improved Lady Thomp-

son (early).

2 PLUM TREES

1 Climax (June).

1 Abundance (July).

7 GRAPE VINES:

1 Moore's Early (July).

2 Concord (August).

1 Niagara (August).

Delaware August).

1 James (October).

1 Scuppernong (October).

Also our 100-page Fruit Manual, if asked for
COLLECTION E-(\$5, Delivered Free.) First-class Strawberry Plants, Asparagus Roots and Horseradish:

$\begin{array}{ll}\text { 1,000 STRAWBERRY } & 300 \text { Klondike (early). } \\ \text { PLANTS: } & \text { 250 Gandy (late). } \\ 50 \text { Dunlop. } & 100 \text { ASPARAGUS ROOTS. } \\ 50 \text { Excelsior. } & 12 \text { HORSERADISH } \\ \text { LORS ThA Thompson. } & \text { ROOTS. }\end{array}$

75 Great Scott.

Also our 100-page Fruit Manual, if asked for.

COI.LECTION F- ( $\$ 5$, Delivered Free.) 1,600 FIRSTCLASS EARLY, MEDIUM AND LATE STRAIVBERRY PLANTS:

400 Excelsior (very early). 200 Dunlop.

300 Lady Thompson. 500 Klondike.

200 Gandy or Aroma (late). 50 Great Scott.

(our choice.)

Also our 100-page Fruit Manual, if asked for.

COLLECTION G.-(\$2.50, Delivered Free.) 12 FIRSTCLASS APPLE TREES:

1 Red June (June).

1 Magnum Bonum (Oct).

ate June). 2 Winesap (fall and winter).

2 Early Ambrosia (Aug.).

2 Grimes' Golden (Sept.).

1 Stayman (fall and winter.

1 Dixie.

COLLECTION H. $-\$ 2.50$, Delivered Free.) 12 FIRSTCLASS PEACH TREES:

1 Neva-Myss.

1 Sneed (June).

1 Greensboro (late June)

1 Carman (July).

1 Belle of Georgia.

1 Burke (late July).

1 Elberta (August).

1 Ambrosia.

1 Crawford (late August).

1 Eaton's Gold (early September).

1 White Heath (late September).

1 Stinson's October (Oct.).

COLLECTION J.-\$2.00, Delivered Free.) 9 FIRSTCLASS APPLE TREES:

1 Red June (June).

1 Early Harvest (July).

1 Early Colton.

1 Summer Ambrosia (Aug.) 1 Dixie (fall and winter).

1 Grimes' Golden (Sept.).

COLLECTION K.-(\$2.00, Delivered Free.) 9 FIRSTCLASS PEACH TREES:

1 Neva-Myss (May).

1 Greensboro (late June).

1 Carman (early July).

1 Belle ofGeorgia (earlyJuly).

1 Elberta (early August).

1 Crawford's Late (late August).
1 Eaton's Gold (early September)

1 White Heath (late September).

1 Stinson's October (Oct.)
THE FOLLOWING COLLECTIONS OF STRAWBERRY PLANTS WILL BE DELIVERED FREE ANYWHERE IN THE UNITED STATES AT PRICES NAMED:

COLLECTION L- $-(\$ 2.50$, Delivered Free.) $500 \mathrm{CHOICE}$ STRAWBERRY PLANTS, early, medium and late varieties.

200 Excelsior (very early). 25 Great Scott.

200 Lady Thompson. 75 Gandy (late).

COLLECTION M,-( $\$ 1.50$, Deliverd Free.) 300 CHOICE STRAWBERRY PLANTS, early, medium and late vaiteties:

100 Excelsior (very early). 25 Great Scott.

$\begin{array}{ll}100 \text { Excelsior (very early). } & 25 \mathrm{Great} \text { Scott. } \\ 100 \mathrm{Lady} \text { Thompson: } & 75 \mathrm{Gandy} \text { (late). }\end{array}$

COLLECTION N.-(\$1.00, Delivered Free.) $150 \mathrm{CHOICE}$ STRAWBERRY PLANTS: 50 Excelsior (very early).

25 Gandy (late) 50 Lady Thompson.

25 Great Scott.

COLLECTION O.-(\$2.50, Delivered Free.) 1 dozen Rose Bushes. Your solection. 

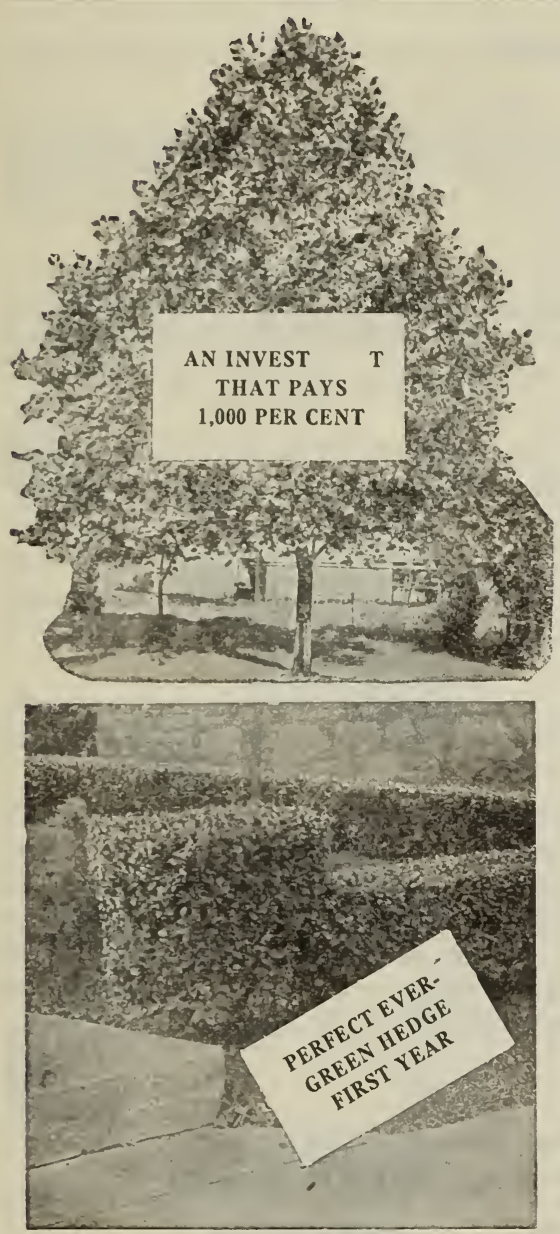

\section{How to Convert a Dwelling Into a Home.}

Billions of the world's money is invested at two and three per cent., four per cent. is considered the highest absolutely safe investment. So powerful is the lure of even wild-cat ventures that promise eight and ten per cent. that the world tumbles over itself in grasping them.

Nevertheless, there is an investment surer even than the two per cent. and that pays 1000 per cent. That is money wisely spent in improving and beautifying the home. A dwelling bare of beautifying outdoor surroundings is now a dwelling disgraced. It no longer ranks with homes at all. But good surroundings are more than a manifestation of refinement. They are an incentive to it. They both indicate and promote the refinement of the dwellers in such a home. If the dwelling is to be rented the return will in the better rent pay immediate return in dollars and cents.

TREES come first. These should be set not less than thirty feet apart and not too near the house, which they will crowd as the years bring growth and spread of limb. Do not set trees too near the hedge. Place them so that any desired door, window, or porch may be shaded from the morning, noon or evening sun according to the exposure. Remember when you plant a tree at your home that you are very likely entering into a lifetime contract with the tree in which you are to furnish sustenance and the tree shade. Don't try to cheat. The tree will beat you at that game every time. As indeed anybody, anything can beat a cheater for the simple reason that he is the biggest of all fools. Get a good tree, dig a deep hole and big one, plant and refill it with only the very best soil and some manure as directed in our Manual. If south of Mason and Dixon's Line the Umbrella tree, the quickest growing and most glorious of all shade trees, must come first. The Silver Maple thrives in all climates. The Pecan makes a noble shade tree, besides its large size and excellent nuts. The Silver Poplar with its leaves of shimmering silver is the most ornamental of all trees. A strong point in favor of all the above shade trees is that a perfect lawn can be maintained under them. In fact, grass grows better under their shade than in the open.

EVERGREEN HEDGES cost less than a fence, ranks next to trees-in increasing the beauty, comfort and money value of a home and will last longer than you will. Around the front yard it can be clipped low, say $2 \frac{1}{2}$ feet. When it is desired to give privacy to a buck yard or to shut off the cold winds it can be trained to quite ten feet. With our plants and booklet you can grow perfect 2 -foot hedge in first year.

ROSES planted along the inside of the hedge and about four feet from it where their wealth of bloom will be in relief upon the green background of the hedge are increased many fold in artistic value. Another most effective arrangement is to plant them next to the house with a background of arbor vitæ. This is especially to be recommended if the house sits up well off the ground. The 
Silver Poplar is also a wonderfully effective ornament set anywhere against a dark green background.

FRUIT.-Now that the world has awakened to the necessity of fruit to good health and indirectly to good morals, it must be a small home plot indeed that is too cramped to grow some fruit of some kind. Even the most transient renter with a sunny spot three feet square can grow a barrel of Never Stop Strawberries.

The Black Tartarian Cherry which make excellent shade trees and bear the finest fruit do well in front and back yard if planted right, and the soil just around them is cultivated for the first two or three years. The Japan Plum, the LeConte or Keifer Pear can be used for the same purposes. If poultry or pigs are kept the plum and ever-bearing Mulberry will both shade and feed them.

In the smallest garden grapes planted along the outer borders and trained against any chance fence or building will bear heavily and take up no room. If there is room for a walk grape vines make the grandest of a trellis over it.

Peach, Plum or Apple Trees can be set in the corners. If the garden is large grapes may be planted and trained over the walks and fruit trees round the outer borders. Raspberries and Blackberries do well in any out-of-the-way corner with little or no cultivation if the old canes are cut off after bearing.

Strawberries and Asparagus do well set as borders along a walk, though a special bed is better. Move the strawberry bed every three years. An asparagus bed once set, and kept free of weeds and grass will last a generation at least.

Every householder should aspire to an orchard be it ever so small as the sine qua non of a true home. If planted right the peach and plum begins to bear the second year; the apple, pear and cherry the fourth year. Plant varieties to ripen in succession as shown in this catalog. The secret of success in planting fruit or shade trees is to dig for each as deep and big a hole as you can afford to, scatter all clay that comes from it afar off and then in planting refill the hole only with rich top soil, mixing in a moderate quantity of well-rotted manure. Never let the manure, especially if new, come next to the tree roots. See our Manual for detailed instructions in planting anything.

\section{NEVA-MYSS (OR EARLY WONDER) PEACH PAYS \$15.00 A TREE.}

We had no peaches here last year except on the Early Wonder. The fruit on the three trees brought in $\$ 45.00$. Alcon County, Miss., March 25, 1912.

IT IS A WONDER.

H. C. MACCOUN. Nowberry County, S. C., January 23, 1912.
Newhe

J. B. O'NEALL HOLLOWAY.

WHAT EARLY WONDER DID IN TEXAS.

Two of the Early Wonder Peach Trees that I ordered of you in February, 1911, have developed twenty-eight fine, luscious commercial peaches in less than sixteen months from date trees were set out. I call that going some. These peaches are truly a wonder to all who have seen them. I am so pleased with them that I shall order more this winter. All that you say about the Early Wonder Peach (so far as my experience has gone) has proved true. I had four other varieties of peaches set out about same time as were the Early Wonder. All bloomed this spring, and most of them fruited more or less, but the Early Wonder were the only ones that held and developed their fruit. The Early Wonder was the latest of the five varieties to bloom. They are certainly beauties, and get their color eight or ten days before they are ripe. You certainly cannot recommend the Early Wonder Peach too highly.

Padacios, Texas, May 30, 1912. Yours very truly, J. W. BELKNAP.

\section{DONE WITH TRAVELING AGENTS.}

I am sending you a list of articles I need. I bought some things from you last fall and quite a lot from a traveling "Agent." Was not at all pleased with what the agent sent, but everything you sent has grown well and looks much better than the others. Shelby County, Tenn.

S. L. CUMMINS.

WILL PULL UP TREES SET AND SET OURS.

Your trees are so fine I will pull up some just set out and set yours. Your trees are great. I ordered $\$ 5.00$ worth. Wayne County, N. C. 
Continental Plant Company, Kittrell, N. C.

\section{Rosebushes.}

(Large, two-year, hardy, field-grown bushes.)

Collection of one dozen best roses (your selection) $\$ 2.50$ delivered free. We to substitute if any kind is sold out.

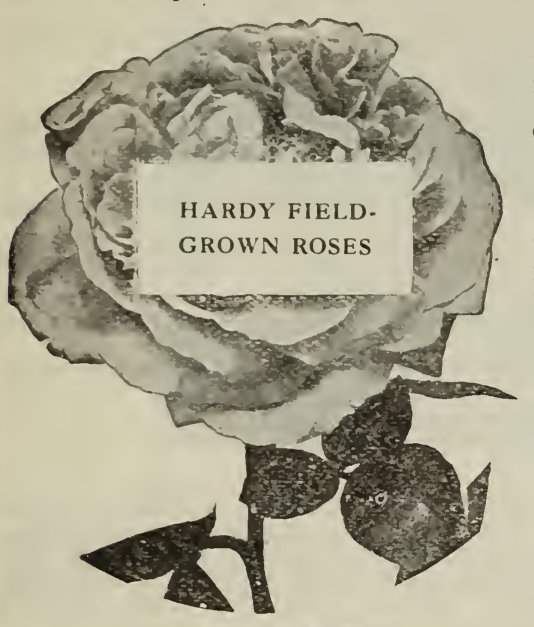

In our list will be found the queens of this queenly flower, varieties selected for their surpassing beauty and for their vigor in producing abundant flowers. We endeavor to give in parenthesis the pronunciation of the French names.

\section{RED ROSES.}

To every buyer of one dozen or more roses we will send free our leaflet, telling how to plant, manure, cultivate, prune and care for them year in and year out.

RICHMOND.-Something distinct in reds. A splendid new rose. 25 cents.

RHEA REID.-Another grand acquisition to the family of glorious red rose.

METEOR.-Vivid, glowing crimson, with a texture of velvet. A truly magnificent rose and a free and constant bloomer. 2.5 cents.

GEN. JACQUEMINOT.-(Gen. Jacmeno.)-A magnificent crimson rose, turning to scarlet; very fragrant. 25 cents.

ETOILLE DE FRANCE.-(A twal duh France,

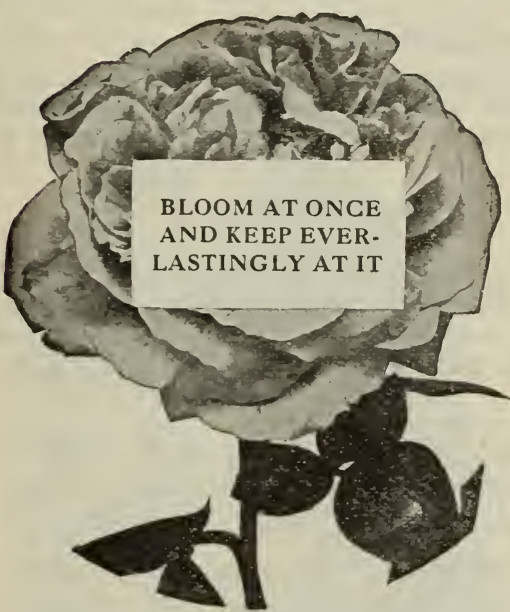

Star of France).-Clear, red, velvety, crimson. Considered by experts to be the handsomest rose in the world. The Gold Medal rose of France. Really a magnificent creation, which no rose connoisseur could afford to miss. 40 cents.

HELEN GOULD.-One of the most famous of all the red roses, and rightly, as it is of great beauty and value. 25 cents.

PAPA GONTIER.-(Pa-Pa Gonto.)-A rich, brilliant red, free-blooming rose. 25 cents.

\section{PINK ROSES.}

PAUL NERON.-(Paul Naron.)-A giant pink rose of grand upright growth and wonderful grace and beauty. 25 cents.

BRIDESMAID.-A fine, deep-pink rose, interesting for its great beauty as well as its sentimental name. 25 cents.

MAMAN COCHET.-(Mama Cochay.)-Among the very finest of all the grand family of pink roses. A truly superb variety. 25 cents.

LA FRANCE.-Another splendid pink rose. 25c.

PINK KILLARNEY.-A splendid rose. Heavy and long blooming. 25 cents.

AURORA.-A grand pink rose, dyed in the tints of the dawn, as its name indicates. 25c. PRESIDENT TAFT. - A superb, deep-tinted pink rose. 25 cents.

W. R. SMITH.-A new creation in magnificent pink roses. 25 cents.

\section{WHITE ROSES.}

THE BRIDE.-Dear to the hearts of rose lovers, not only for its sentimental name, but for its own $\mathrm{g}$ orious white self. 25 cents.

WHITE LA FRANCE. - A pure white rose with a shading of fawn color. 25 cents.

KAISERIN (Kiserine) AUGUSTA VICTORIA. - Considered by many the grandest white rose in the world. 25 cents.

MARIE GILLOT.-(Marry Guiyo).-One of the best bearers and most beautiful of all the white roses. 25 cents.

WHITE KILLARNEY.-The cream of the new white roses. 25 cents. 


\section{YELLOW ROSES.}

PERLE DE JARDINS.-(Pearl duh Zhardeen; Pearl of the Garden.) A clear, rich, goldien yellow rose. 25 cents.

MLLE. F. KRUGER.-A very deep-yellow rose, srtikingly handsome. 25 cents.

ETOILE DE LYON.-(Atwahl duh Lyon, Star of Lyons).-Deep golden yellow. A double rose. A magnificent bloomer. 25 cents.

BLUMENSCHMIDT.-One of the grand new roses. White with just a hint of pink. 25c.

\section{CLIMBING ROSES.}

MARECHAL NEIL.-(Marshal Neel.)-All in all, this is the most popular of all roses, as it is the most refinedly beautiful. Blooms an indescribable tint of yellow that is most beautiful. Graceful climbing vines no less so. Verily, all in all, a poem in roses. 40 cents.

YELLOW RAMBLER.-A luxuriant grower and heavy bearer of beautiful yellow roses. 25 cents.

CLIMBING METEOR.-Blooms deep, vivid, velvety crimson, studding its beautiful vine like living meteors. A beautiful thing. 25 cents.

CRIMSON RAMBLER. - A rampant grower and most profuse bloomer of flaming red blooms. 25 cents.

WHITE RAMBLER.-A rapid climber and grower, bearing clusters of snow-white roses. 25 cepts.

MRS. ROBERT PERRY.-A superb white climbing rose.

\section{VIOLET PLANTS.}

Another flower woven with the very web and woof of human sentiment is the shyly beautiful violet. Grown in beds it is fine. It is especially valuable to border walks and beds, where its vivid green foliage all 'the year round, except the very dead of winter in cold climates, adds greatly to the general effect of the finest lawns or gardens, and equally well adorns the walk to the humblest cabin. 100 plants, $\$ 1.00$.

\section{PONDEROSA LEMON PLANTS.}

This evergreen pot plant is not only a beautiful ornament to any room in the house, as it can stand a very low temperature, but a most attractive curiosity; the enormous flaming yellow fruit it bears weighing sometimes as much as four pounds; and they make excellent lemonade withal. Price, 50 cents.

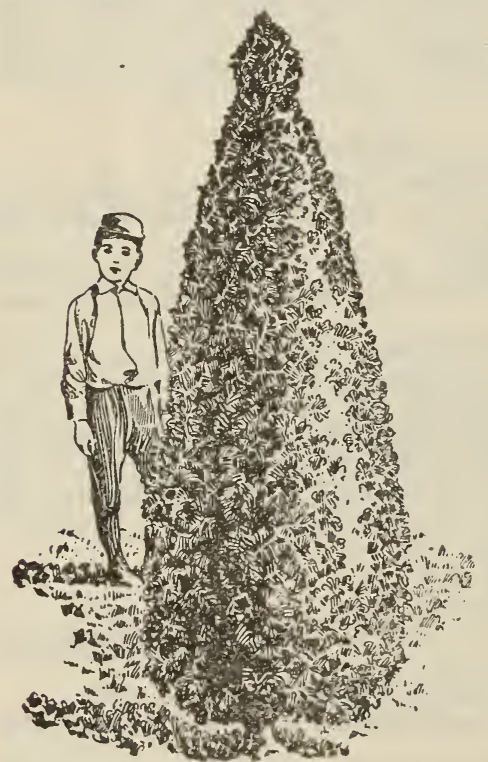

An excellent representation of the magnificent Pyramidal Arbor Vitae.

\section{Evergreens.}

Pyramidal and American Arbor Vitæ and Norway Spruce we can ship in splendid, extra large sizes, with hills of earth attached to roots and wrapped in burlaps, at $\$ 1.00$ each. Medium size, 50 cents. See below.

PYRAMIDAL ARBOR VITAE.-This is one of the handsomest and thriftiest of the evergreen family. Succeeds where even other kinds fail. 50 cents.

NORWAY SPRUCE.-The most popular of the spruce family. Grows twenty or thirty feet tall, throwing out a mass of graceful leaves from the ground to its tapering point. 50 cents.

AMERICAN ARBOR VITAE.-Lower growing and more bushy in its habits than the Pyramidal. Fine to plant singly on lawns. Makes a hedge of surpassing beauty. 50 cents.

MAGNOLIA GRANDIFLORA.-Famous the world over for its magnificent foliage and blossoms and for their great fragrance. Grows into a large tree and lasts for centuries. $\$ 1.00$. 


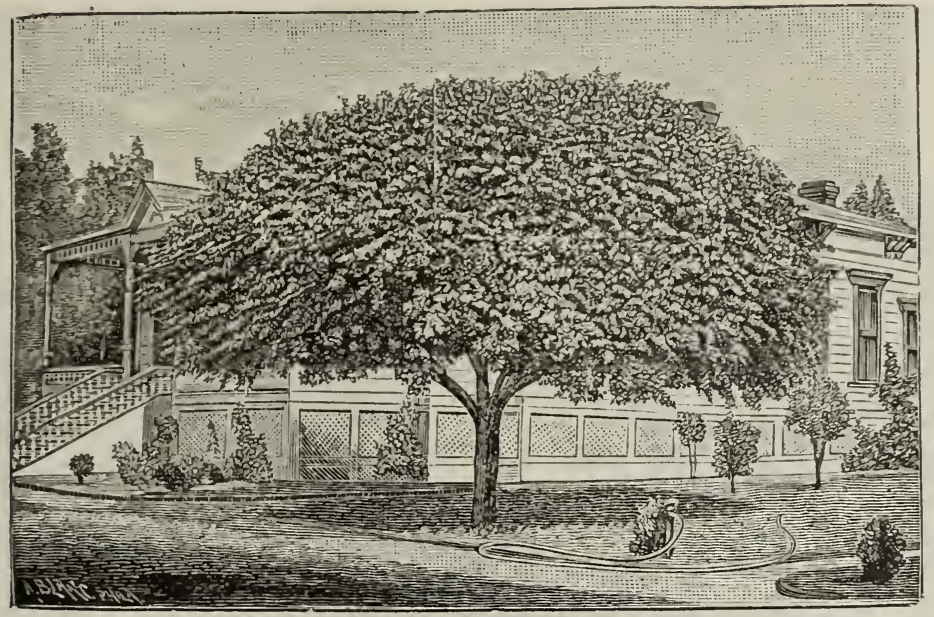

UMBRELLA TREE. Handsomest tree on the planet, and with good stock, one of the quickest to grow.

TEXAS UMBRELLA TREES.-(See also picture on following page and on last outside cover page.) No tree in the world surpasses this in gracefulness and beauty, and none makes a denser shade, or makes it quicker. It makes a great growth, attaining a large size, and lasts for many years. We have some that were planted thirty-five years ago and are still in their prime. They are considered the most striking and beautiful things in town. 2 years, 50 cents.

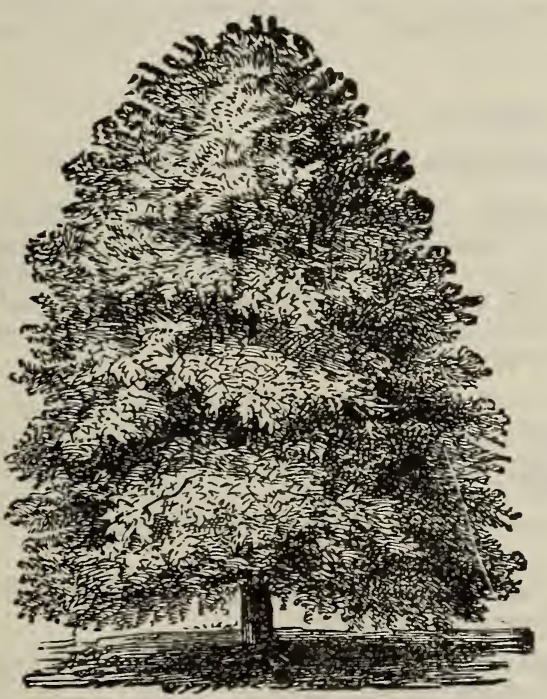

Maple.

SILVER MAPLE. - This is the quickest growing of all the maple family, and a very handsome tree, making a dense shade. 5 to 7 feet, 25 cents; 8 feet and over, 50 cents.

SUGAR MAPLE. -This is not as fast a grower as the Silver Maple, but it is the standard shade tree over a large region. 50 cents.

SILVER POPLAR.-A quick-growing tree, with trunk and leaves of beautiful silvery sheen Highly ornamental on a lawn, being one of the handsomest of trees. 50 cents.

PERFECT EVERGREEN HEDGE THE FIRST YEAR.-The quickness with which a hedge can be grown from the plants we offer is another strong point in its favor. Plants set in fall, winter or early spring and well manured and cared for will the following summer make a hedge two and a half feet high and as solid from the ground as a stonewall, and as smooth, if kept trimmed. This is a good height to keep a hedge for ordinary purposes, for yards and small lawns. However, it can be grown any height up to ten feet or more to answer the purpose desired, being thus valuable to give privacy to a yard or as a wind-break to shut off cold winds from a yard or lot.

AMOOR RIVER PRIVET.-CALIFORIA PRIVET.-We can furnish either of these, either of which will make a close, compact hedge, solid from the ground up. That is, if our directions are followed. We issue a special folder on planting, manuring and pruning these hedges. It is free to every buyer of 100 hedge plants or over if asked for. We sell only large, strictly first-class plants, which will make a perfect hedge the first year. Nearly everybody prefers them to lower grade plants, which if a little cheaper are so much smaller that it will take a year longer to make a hedge.

Before shipment all hedge plants are cut back to the ground, the proper height for planting. This also saves freight. Those desiring to cut them back themselves will please so state in ordering. Cut back they must be.

Plenty of well rotted stable manure at planting and plenty of water all through summer will make a good tree In three years. But soe page 28 as to manuring a tree. 


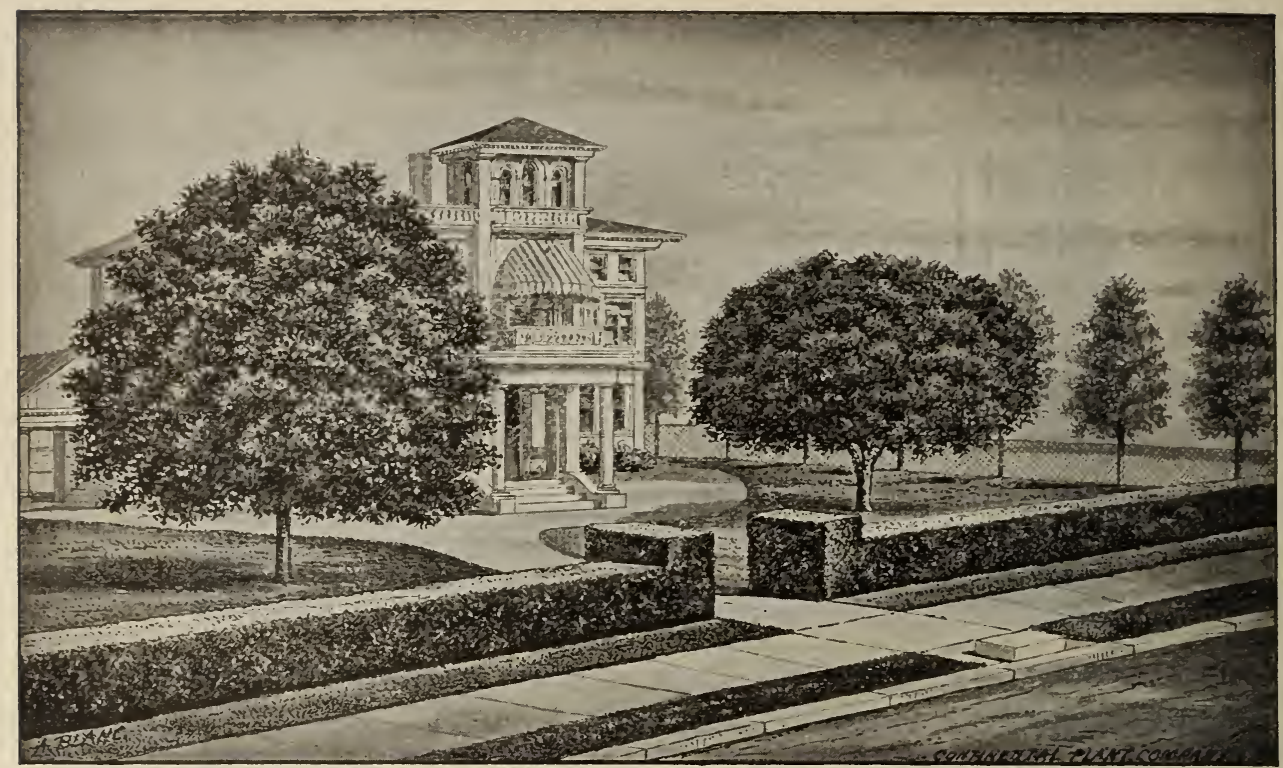

Silver Maple.

Umbrella, Handsomest of all Shade Trees.

Shows the grandly ornamental effect of evergreen privet hedge (solid as a stone wall), Silver Maple and Umbrella Tree. The hedge can be pruned low or high as a wind-break or to give privacy to a back yard. Can be grown first year from our heavily rooted hedge plants. See Page 31.

\section{Items De Luxe.}

\section{Choice Fruits For Home Use and High-grade Fancy Market. (See also page 25.)}

NEVER STOP, EVER-BEARING STRAWBERRY.-Most exquisitely flavored of all fruits. Under high cultivation pays $\$ 2,500$ an acre. Planted in garden, fruits from earliest spring till dead of winter-being proof to ordinary frosts. At South, in ordinary winters, with little straw protection in cold snaps, will fruit through the cold months and the year round. Planted in a barrel and carried in doors in fall can be fruited all winter in coldest climate. Thus grown, forms charming ornament for greenhouse or sunny conservatory.

100 plants, $\$ 2.50$, delivered free anywhere, with booklet, making success certain.

NEVA-MYSS (OR EARLY WONDER) PEACH.-Far and away the earliest peach known. Large, brilliant red, soft, good flavor. Belongs to a class of its own and not to that of the small, colorless, insipid early peach. Never fails to bear good crop, for while earliest to ripen it is the last to bloom. Six trees, $\$ 2.50$, delivered free anywhere. Guaranteed to succeed everywhere.

AMBROSIA PEACH.-White, rosy cheeked, soft, luscious, melting. Most delicious flavored of all peaches. July. Six trees, $\$ 2.50$, delivered free anywhere.

SUMMER AMBROSIA APPLE.-A medium size, golden flecked red apple of the finest imaginable flavor. August. Six trees, $\$ 2.50$, delivered free anywhere.

FALL AMBROSIA APPLE.-A very large pippin-shaped apple. Equal, and if possible superior, in flavor to Summer Ambrosia. Fall and winter. Six trees, $\$ 2.50$, delivered free anywhere.

DIXIE APPLE.-A superb fall and winter apple that originated at the South and will no doubt, succeed farther South than other kinds. Six trees, $\$ 2.50$, delivered free anywhere.

(See page 8 for only conditions under which Never Stop and Neva-Myss are sold.) 


\section{PRICE-LIST.}

STRAWBERRY PLANTS. - Well rooted, vigorous plants, all grown from parent plants not only not allowed to weaken themselves by fruiting last spring, but which just before planting were "stripped to the bone" and dipped in a strong liquid fungicide. This renders the plants they produced free from the rust and fungous diseases which annually lessen the strawberry crop of the country 10 to 30 per cent. See page 6.

THESE PRICES CASH WITH ORDER.-What bookkeeping and bad debts cost we give the cash buyer In low prices and quality

\begin{tabular}{|c|c|c|c|c|c|c|c|c|}
\hline $\begin{array}{l}\text { All lots from } 50 \text { up can be selected } \\
\text { from as many varieties as buyer } \\
\text { chooses, but not less than } 25 \text { of } \\
\text { each. }\end{array}$ & $\begin{array}{l}\text { Per } 1,000 \\
\text { In lots of } \\
10,000 \text { and } \\
\text { over. }\end{array}$ & $\begin{array}{c}\text { Per } 1,000 \\
\text { in lots of } \\
5,000 \text { to } \\
10,000\end{array}$ & $\begin{array}{c}\text { Per } 1,000 \\
\text { in lots of } \\
3,000 \text { to } \\
5,000\end{array}$ & Per 1,000 & Per 500 & Per 100 & Per 50 & Per 25 \\
\hline $\begin{array}{l}\text { xcelsior (Per.) The Standard } \\
\text { Extra Early Berry (see page }\end{array}$ & - & & & & & & & \\
\hline 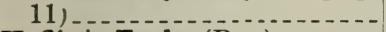 & $\$ 1.90$ & $\$ 2.10$ & $\$ 2.25$ & $\$ 2.50$ & $\$ 1.60$ & $\$ .65$ & $\$ .50$ & \\
\hline Heflin's Early (Per.) & 1.90 & 2.10 & 2.25 & 2.50 & 1.60 & .65 & .50 & .40 \\
\hline Virginia (Imp.) & 3.00 & 3.00 & 3.00 & 3. & 2.00 & .65 & .50 & .40 \\
\hline $\begin{array}{l}\text { Iissionary } \\
\text { mproved Lady Thompson }\end{array}$ & 1.90 & 2.10 & 2.25 & 2. & 1.60 & .65 & .50 & .40 \\
\hline (Per.) & 1.90 & 2.10 & 2.25 & 2.50 & 1.60 & .65 & .50 & .40 \\
\hline KLONDYKE (Per.) - & 1.90 & 2.10 & 2.25 & 2.50 & 1.60 & .65 & .50 & .40 \\
\hline Brandywine (Per.). & 3.00 & 3.10 & 3.10 & 3.10 & 1.75 & .75 & .50 & .40 \\
\hline Dunlop (Per.) - - & 1.90 & 2.10 & 2.25 & 2.50 & 1.60 & .65 & .50 & .40 \\
\hline Warfield (Imp.). & 1.90 & 2.10 & 2.25 & 2.50 & 1.60 & .65 & .50 & .40 \\
\hline land (Imp.) & 2.50 & 2.50 & 2.50 & 2. & 1. & .65 & .50 & .40 \\
\hline (Per.) & 1.90 & 2.10 & 2.25 & 2. & & .75 & .50 & .40 \\
\hline Aroma (Per.) & 3.00 & 3.00 & 3.00 & 3.00 & 2.00 & .65 & .50 & .40 \\
\hline Mar & $\ldots$ &.-- & ----- & $--\cdots-$ & 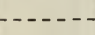 & 1.00 & ----1 & - . - - - \\
\hline Arms & $\ldots$ & 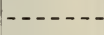 & $\ldots$ & $\ldots$ & $\cdots$ & 1.00 & ---- & $\ldots . .$. \\
\hline $\begin{array}{l}\text { Never } 5 \text { top (The wonderful ever- } \\
\text { bearer, } 100 \text { plants } \$ 2.50 \text { delivered } \\
\text { free. Not less than } 100 \text { sold). }\end{array}$ & & & & & & & & \\
\hline
\end{tabular}

fre日. Not less than 100 sold).

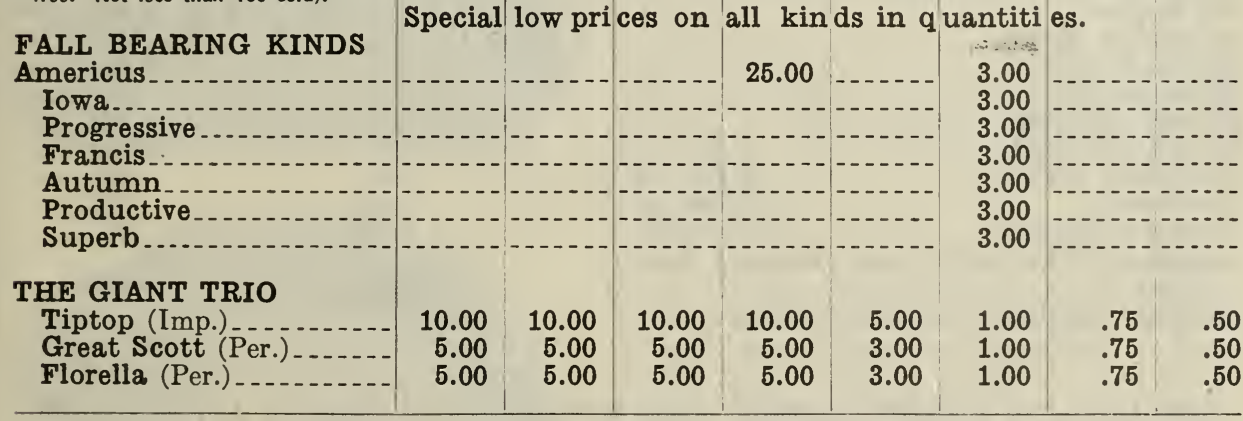

The above list includes only the leading or standard varieties. In addition we have tested most of the countless new varieties that have come out in the past quarter of a century. The above (about one in a thousand) are the cream of all these varieties.

Varietles of strawberry plants marked (Imp.) have imperfect or pistillate blooms and should have every fourth row of the field planted In a (Per.) perfect or staminate blooming kind. If preferred the bundles can be opened and the two kinds thoroughly mixed in above proportion and thus planted. Some of the heaviest and surest bearing varieties ever known are imperfect or pistillate.

Never-Stop Strawberry Plants and Neva-Myss Peach Trees are sold only under restrictions. (See Page 8.)

STRAWBERRY PLANTS SHIPPED UP TO JUNE 15TH. - In the sounthern and central parts of the country they can be set any time during fall, winter or spring that the ground is not actually frozen or miry the earlier the better. To those who can not plant early and to northern persons we can now ship up to June 15th plants in a perfectly dormant state guaranteed to arrive by express in perfect condition and which properly set will live and grow off rapidly no matter how hot and dry it is. See page 3 for plants by freight at a cost of 25 cents per 1000 All orders for late shipments should be placed as early as possible and order must call for dormant plants. 
Dozen, 25, 50 or 100 lots can be selected from as many varieties at same price, as buyer chooses.

\begin{tabular}{l|c|c|c|c|c}
1,000 & 500 & 100 & 50 & 25 & $\mathrm{D}$. \\
\hline & & & & \\
\hline
\end{tabular}

Apple Trees (see p. 16). All varieties, except the five following. (Special price in quantities) ..

Dixie, Early Colton Ellis Ever bearing, Summer Ambrosia, Fall Ambrosia..... Peach Trees (see page 12). All varieties, except the four following and Niagara. (Special low price in quantities)

Japan Plum Trees (see page 15)

See pp. $25 \& 32$.

Apricot Trees (see page 15).

Everbearing Mulberry Trees (see page 19) -

\begin{tabular}{l|l|l|l} 
& 10.00 & 5.00 & 2.75
\end{tabular}

Cherry Trees (see page 20 ;) ......

Pear Trees (see page 19) Keiffer

Pecan Trees (see page 21) Paper-shell kinds

Pecan Trees-Seedling Trees

Japan Walnuts (see page 26)

Shade Trees. Umbrella Trees, Sugar Maple. Silver Maples. Large, 50; medium
vergreens. American and Pyramidal Arbor

Vitæ, Norway Spruce (see page 20)

Magnolia Trees. Very fine (3 to $4 \mathrm{ft}$. high).

Evergreen Hedge Plants, large. Makes perfect

Hedge first year (see page 32)

Rosebushes (25c. to 40c. See page 22)

Violet Plants (see page 23)
Grapevines. Concord, Delaware, Moore's

Early Niagara (see page 29)

Grapevines. (Scuppernong and James)

Fig Bushes..... 5.00

Asparagus Roots.

Rhubarb Roots....

Horseradish

Currant Bushes

Gooseberry Bushes

Raspberry Plants

Blackberry

Dewberry Plants

Raspberry Plants-St. Regis, the great ever-

bearer.

Cabbage Plants (see page 35 for prices).

\section{SPECIAL LOW PRICES ON FALL AND WINTER VARIETIES OF APPLE TREES IN QUANTITIES.}

LOW EXPRESS RATES-Being one of the largest shippers, the express company allows us 30 per cent. off the regular rates. We pack lightly, and spare no pains to save our customers every cent possible in transportation.

All orders for trees for less than $\$ 1.00$ must include 25 cents extra to cover actual cost of packlng. All larger tree orders and all other orders packed freo.

BE SURE TO GIVE THE NUMBER OF YOUR ORDER if you should have occasion to write about it. If you do not, we cannot possibly find It among the thousands on our books. Number is given on acknowledgment postal we mail upon recelpt of order.

TO MAKE SURE OF GETTING JUST WHAT YOU WANT It Is always best to send in your order as soon as you receive this catalogue. First-class stock will then be reserved for you and shlpped when directed.

Time of shlpment of frult trees, shade trees, hedge plants, rose bushes, grape vines, etc., etc., from October 15 th to April 15 th. 


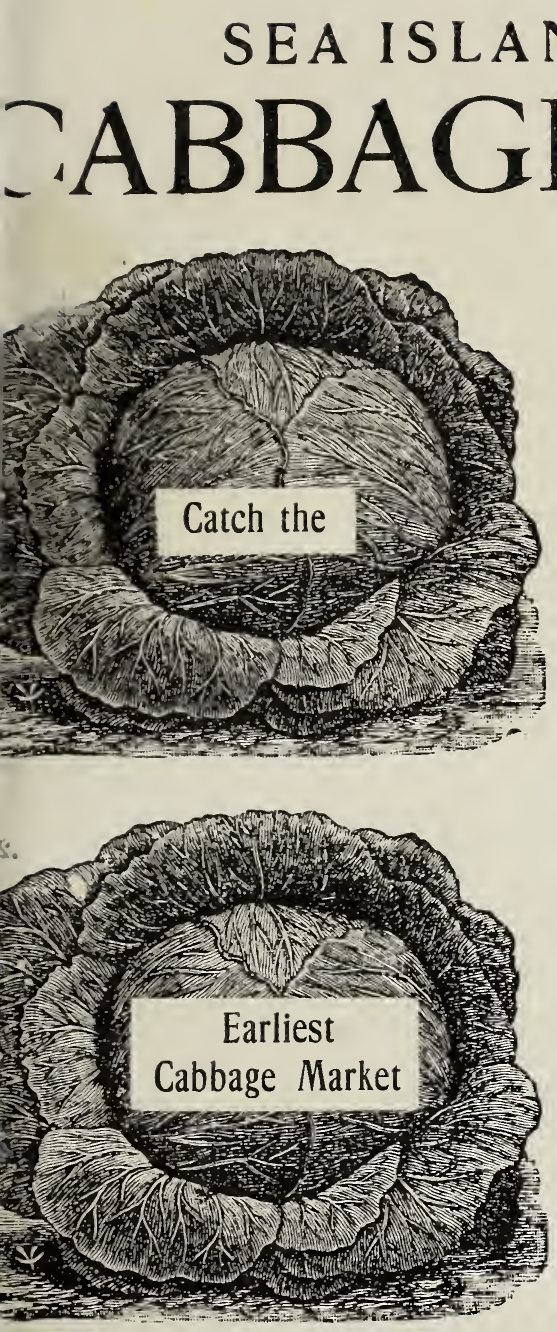

SURE TO LIVE because they are hardened by being grown in the open air in mid-winter. This is practicable only on the islands of the South Carolina coast where the cold, steady sea winds harden the plants at the same time that they prevent the formation of frost. A young cabbage plant will stand a moderate freeze while the deposit of white frost on the leaves means death.

SURE TO HEAD because in this favored region the seed can be sown in mid-winter and at just the time when Old Mother Nature will make cabbage out of the product instead of running them up into blooms. Why this is we know not. We only know it is her way, and she always has her way. Many a promising setting of plants liave we known, which grown from seed planted too early, ended in a flow er garden (and profanity) instead of a cabbage patch.

SURE TO PAY because they head ten days to two weeks earlier than plants grown under glass or in cold frames. They head earlier because they are so hardy that they can safely be planted any where in the country in mid-winter on any day that the soil is not actually frozen. Subsequent frosi or freezes will not harm them. The roots at once take hold and assimilate the fertilizer and grow whenever the soil is not frozen. When spring comes the plants are firmly rooted and ready to get right down to business, making heads as solid as cannon balls.

Our plants are grown by the most experienced grower on the South Carolina coast, and shipped direct from grower to purchaser. Special express rate is very low. We can fill orders any time from December 1 to April 15.

PrICE--F. O. B. Express Office, Charleston, S. C.: Lots of 1,000 to $5,000, \$ 1.50$ per thousand; 5,000 to 9,000, $\$ 1.25$ per thousand; 10,000 and over, $\$ 1.00$ per thousand. Plants are packed in cases holding either $500,1,000$ or 2000 plants to case. Order in these quantities. Five hundred plants of one variety sold at the 1,000 rate.

One pound of ordinary soap dissolved in four gallons of warm water and sprinkled on the cabbage will drive off all bugs and insects and do no harm to the cabbage.

VARIETIES; - Early Jersey Wakefield (earliest); Charleston Large Type Wakefield (second earliest); Succession (earliest flat head) and Short-stemmed Flat Dutch (largest and latest.)

\section{SPLENDID RESULTS FROM OUR CABBAGE PLANTS}

Two years ago we bought cabbage plants of you and got splendid results. Last year we bought elsewhere and ults were poor.

C. S. McGINTY \& SON, Warren County, Ga. 
